\title{
Pharmacological inhibitors of anaplastic lymphoma kinase (ALK) induce immunogenic cell death through on-target effects
}

\author{
Adriana Petrazzuolo ${ }^{1,2,3}$, Maria Perez-Lanzon ${ }^{1,2,3}$, Isabelle Martins ${ }^{1,2}$, Peng Liu (iD ${ }^{1,2}$, Oliver Kepp (iD ${ }^{1,2}$, Véronique Minard-Colin ${ }^{4}$, \\ Maria Chiara Maiuri (iD) ${ }^{1,2}$ and Guido Kroemer (iD ${ }^{1,2,5,6,7 凶}$
}

(c) The Author(s) 2021

Immunogenic cell death (ICD) is clinically relevant because cytotoxicants that kill malignant cells via ICD elicit anticancer immune responses that prolong the effects of chemotherapies beyond treatment discontinuation. ICD is characterized by a series of stereotyped changes that increase the immunogenicity of dying cells: exposure of calreticulin on the cell surface, release of ATP and high mobility group box 1 protein, as well as a type I interferon response. Here, we examined the possibility that inhibition of an oncogenic kinase, anaplastic lymphoma kinase (ALK), might trigger ICD in anaplastic large cell lymphoma (ALCL) in which ALK is activated due to a chromosomal translocation. Multiple lines of evidence plead in favor of specific ICD-inducing effects of crizotinib and ceritinib in ALK-dependent ALCL: (i) they induce ICD stigmata at pharmacologically relevant, low concentrations; (ii) can be mimicked in their ICD-inducing effects by ALK knockdown; (iii) lose their effects in the context of resistance-conferring ALK mutants; (iv) ICD-inducing effects are mimicked by inhibition of the signal transduction pathways operating downstream of ALK. When ceritinib-treated murine ALK-expressing ALCL cells were inoculated into the left flank of immunocompetent syngeneic mice, they induced an immune response that slowed down the growth of live ALCL cells implanted in the right flank. Although ceritinib induced a transient shrinkage of tumors in lymphoma-bearing mice, irrespective of their immunocompetence, relapses occurred more frequently in the context of immunodeficiency, reducing the effects of ceritinib on survival by approximately $50 \%$. Complete cure only occurred in immunocompetent mice and conferred protection to rechallenge with the same ALK-expressing lymphoma but not with another unrelated lymphoma. Moreover, immunotherapy with PD-1 blockade tended to increase cure rates. Altogether, these results support the contention that specific ALK inhibition stimulates the immune system by inducing ICD in ALKpositive ALCL.

Cell Death and Disease (2021)12:713; https://doi.org/10.1038/s41419-021-03997-x

\section{INTRODUCTION}

Cancer has been conceived as an essentially cell autonomous disease (caused by [epi]genetically unstable cancer cells that proliferate, invade and disseminate) [1] until it became clear that cancer cells also need to elude immune control to generate invasive tumors [2]. Indeed, in normal tissue homeostasis, aberrant cells are eliminated by innate immune effectors (such as NK cells) or even elicit cognate immune responses (mostly by cytotoxic $\mathrm{T}$ lymphocytes) [3, 4]. In contrast, immunosuppression governs invasive tumors. Genetic tumor aberrations guide immune escape, recruiting immunosuppressive macrophages or myeloid-derived suppressor cells $[5,6]$ or hiding tumor cells from recognition (downregulating class I major histocompatibility complex) [7].

In this context, an authentic paradigm shift has occurred over the past decade. Beyond the idea that anticancer drugs must kill or paralyze the malignant cells themselves, an ever-increasing armamentarium of immuno-oncology drugs is being developed to stimulate (or unblock) immune responses against tumorassociated antigens [8]. For example, immune checkpoint inhibitors that target the immunosuppressive PD-1/PD-L1 interaction are being approved for ever more oncological indications, across a wide spectrum of malignant disease [9-12].

Curiously, it turned out that many (relatively) successful anticancer chemotherapeutics do not only kill neoplastic cells but rather succeed in inducing potent and clinically relevant antitumor immune responses. Often, such effects are obtained through the induction of immunogenic cell death (ICD), a cell death modality that arises in the context of apoptosis [13], necroptosis [14], pyroptosis [15], or ferroptosis [16]. Apoptotic (caspase-dependent) ICD is characterized by a series of stereotyped changes in which danger-associated molecular patterns (DAMPs) are exposed on the cell surface or released into the extracellular space. Cell surface-exposed DAMPs include calreticulin (CALR), which usually is present in the lumen of the

\footnotetext{
${ }^{1}$ Centre de Recherche des Cordeliers, INSERM UMRS1138, Université de Paris, Sorbonne Université, Team "Metabolism, Cancer \& Immunity", 75006 Paris, France. ${ }^{2}$ Cell Biology and Metabolomics platforms, Gustave Roussy Cancer Campus, 94805 Villejuif, France. ${ }^{3}$ University Paris Saclay, Faculty of Medicine, 94270 Kremlin Bicêtre, France. ${ }^{4}$ Department of Pediatric and Adolescent Oncology, Gustave Roussy, Université Paris-Saclay, 94805 Villejuif, France. ${ }^{5}$ Pôle de Biologie, Hôpital Européen Georges Pompidou, AP-HP, 75015 Paris, France. ${ }^{6}$ Suzhou Institute for Systems Medicine, Chinese Academy of Sciences, Suzhou, Jiangsu 215163, China. ${ }^{7}$ Karolinska Institute, Department of Women's and Children's

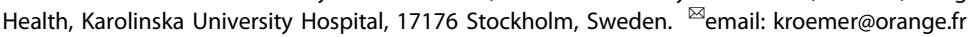
Edited by G. Melino
} 
endoplasmic reticulum, yet translocates during ICD to the external side of the plasma membrane and then acts as a potent 'eat-me' signal for dendritic cells (DCs) [17]. Released DAMPs include adenosine triphosphate (ATP), which is a chemoattractant for DC precursors [18], high mobility group box 1 (HMGB1), which is a maturation/activation factor for DCs [19], and type I interferons that attract $T$ lymphocytes into the tumor bed [20]. Altogether, a spatiotemporal sequence of DAMPs orchestrates the recruitment of DCs into the tumor, the uptake of tumor antigens by DCs, and the cross-presentation of such antigens to cytotoxic T lymphocytes. The latter then launch an attack against residual cancer cells and are responsible for the long-term outcome of ICD-inducing chemotherapies beyond treatment discontinuation.

ICD has become a therapeutically important cell death modality because some ICD-relevant biomarkers inform on the prognosis of cancer patients. For example, the loss of CALR expression by cancer cells correlates with dismal prognosis in acute myeloid leukemia [21], colorectal cancer [22], non-small cell lung cancer [23], and ovarian carcinoma [24]. The absence of extracellular ATP (e.g., due to the overexpression of ATP-degrading enzymes), the suppression of HMGB1 expression and the subversion of type I interferon responses also have a negative prognostic impact [25-27].

The idea that anticancer agents can ignite therapeutically relevant antitumor immune responses has been extended to so-called 'targeted' agents, hitting genetic abnormalities unique to cancer cells $[28,29]$. Thus, the first tyrosine kinase inhibitor (TKI) that was introduced into the clinic, imatinib mesylate [30], an inhibitor of oncogenic breakpoint cluster region-abelson tyrosine protein kinase, $B C R-A B L$, and C-KIT, turned out to exert (part of) its activity against gastrointestinal stromal tumors (which depend on oncogenic C-KIT) by harnessing the immune system [31-33]. Imatinib mesylate negatively regulates indoleamine 2,3-dioxygenase expression in tumor cells, reducing immunosuppressive tryptophan metabolites in the tumor bed, hence increasing cytolytic T lymphocytes influx and activation [34]. In addition, a recent screen for TKI with ICD-inducing properties led to the identification of crizotinib (used for the treatment of tumors that depend on anaplastic lymphoma kinase, ALK, mesenchymal-epithelial transition factor, c-MET or ROS1), as an ICD-inducing agent, though through off-target effects [35]. Thus, crizotinib induced ICD in cells that lacked the oncogenic kinases that it normally inhibits, and only at doses $\geq 10 \mu \mathrm{M}$, far above the threshold of specificity [35].

Here, we examined the possible on-target effects of crizotinib as TKI specifically inhibiting ALK, using ALK-positive anaplastic large cell lymphoma ( $\mathrm{ALK}^{+} \mathrm{ALCL}$ ) as a model, where $\mathrm{ALK}$ is expressed and activated following a chromosomal translocation $(\mathrm{t}(2 ; 5))$ leading to the fusion with nucleophosmin 1 (NPM1) [36]. Hence, we investigated the possible pro-ICD and immunogenic effects of ALK kinase inhibitors on an ALK-dependent cancer. We show that such TKIs indeed can trigger ICD through on-target effects.

\section{RESULTS}

\section{ALK inhibitors induce immunogenic cell death in vitro}

NPM1-ALK-positive $\left(\mathrm{NPM1-ALK}{ }^{+}\right.$) tumors rely on ALK kinase activity for survival and proliferation. Thus, ALK inhibition causes tumor cells to halt proliferation and die [37]. We quantified cell death induced by ALK inhibitors using a cytofluorometric approach. This method measures two major features of cell death: the initial loss of mitochondrial transmembrane potential $\left(\Delta \Psi_{m}\right)$ and the subsequent loss of the plasma membrane integrity, using 3,3'-dihexyloxacarbocyanine iodide $\left(\operatorname{DiOC}_{6}(3)\right)$ and $4^{\prime}, 6$ diamidino-2-phenylindole (DAPI) as fluorescent dyes, respectively. Over the course of cell death, as $\Delta \Psi_{m}$ is lost, $\operatorname{DiOC}_{6}(3)$ staining intensity decreases; whereas loss of membrane integrity facilitates DAPI staining. Crizotinib and ceritinib, which are first and second generation ALK inhibitors, respectively, reduced the number of live NPM1-ALK ${ }^{+} \mathrm{ALCL}$ cells $\left(\mathrm{DiOC}_{6}(3)^{+} \mathrm{DAPI}^{-}\right)$, triggering cell death in a dose- and time-dependent manner (Fig. 1A, B, S1). Cell viability was partially rescued by the pan-caspase inhibitor Q-VD$\mathrm{OPh}$, implying that crizotinib- and ceritinib-induced cell death was apoptotic (caspase-dependent) (Fig. S2). On the contrary, the NPM1-ALK-negative (NPM1-ALK) FE-PD and MAC-1 cells were insensitive to ALK inhibitors, which caused cell death only at the highest concentration tested $(5 \mu \mathrm{M})$ and later in time $(48 \mathrm{~h})$ when compared to NPM1-ALK ${ }^{+}$cells (Fig. 1A, B, S1). Thus, low concentrations of ALK inhibitors $(\leq 2 \mu \mathrm{M})$ have specific effects on NPM1-ALK ${ }^{+}$but not NPM1-ALK ALCL cells.

We proceeded exploring the potential immunogenicity of crizotinib- and ceritinib-induced cell death, testing their capability to trigger the surrogate markers of ICD. First, when added to SUDHL-1 (Fig. 1C-G) or SUP-M2 (Fig. S3) cells, crizotinib and ceritinib caused CALR translocation from the endoplasmic reticulum to the plasma membrane (Fig. 1C, D, S3A, B). Moreover, both inhibitors significantly induced ATP secretion (Fig. 1E, S3C) and HMGB1 release (Fig. 1F, S3D) into the extracellular space. Finally, crizotinib upregulated two pivotal genes of the type I interferon signature, interferon beta 1 (IFNB1) and C-X-C motif chemokine ligand 10 (CXCL10) at the mRNA level (Fig. 1G, S3E). Altogether, our data suggest that crizotinib and ceritinib cause immunogenic cell death of ALK-dependent tumors.

\section{Specific ALK inhibition causes immunogenic cell death}

Crizotinib and ceritinib inhibit ALK, as well as other tyrosine kinases (such as ROS1, MET, or Insulin Like Growth Factor 1 Receptor) [38]. Therefore, we attempted to rule out off-target effects of these ALK inhibitors, using two different approaches. In a first set of experiments, we used a human NPM1-ALK ${ }^{+}$ALCL cell line (SU-DHL-1 TTA) expressing a doxycycline-inducible shRNA against ALK [39]. After doxycycline addition, SU-DHL-1 TTA cells downregulated ALK, halted proliferation and finally died (Fig. 2A-D). In parallel, they externalized CALR (Fig. 2C, D), secreted ATP and released HMGB1 (Fig. 2E, F) into the extracellular milieu. Thus, genetic (non-pharmacological) inhibition of ALK had similar effects as low-doses crizotinib and ceritinib.

In a second set of experiments, we took advantage of an NPM1$\mathrm{ALK}^{+}$cell line resistant to crizotinib (SUP-M2 CR03) because of a point mutation in the ALK kinase domain that impairs crizotinib binding [40]. As expected, SUP-M2 CR03 resisted crizotinibinduced cell death compared to the parental cell line (Fig. 2G). Concomitantly, a trend for these crizotinib-resistant cells to show less CALR on their surface and release less ATP and HMGB1 than the parental cell line upon challenge with the TKI was clear (Fig. $2 \mathrm{H}-\mathrm{J}$ ). Hence, an ALK mutation that confers resistance to crizotinib-induced cell death also attenuated the stigmata of ICD.

Altogether, these data strongly argue in favor of direct on-target effects of ALK inhibitors with respect to the induction of the surrogate markers of ICD.

\section{Pathways downstream of ALK mediate immunogenic cell death}

Constitutively active ALK is a clinically relevant oncogene because it ignites several downstream molecular pathways, driving malignant transformation and promoting tumor cell survival and proliferation [41] (Fig. 3A). We wondered which molecular pathway might account for ICD. Therefore, we pharmacologically inhibited each pathway by using inhibitors of PI3K/mTOR, PI3K, ERK1/2, STATs, and PLCY (BEZ235, BKM120, PD0325901, Stattic, and U73122, respectively). All these pharmacological inhibitors killed SU-DHL-1 cells, whereas SUP-M2 cells proved to be resistant to the ERK1/2 inhibitor PD0325901, as previously reported [42] (Fig. 3B). However, only BEZ235, BKM120, PD0325901 induced death of SU-DHL-1 cells, and only BEZ235 and BKM120 killed SUPM2 cells in a dose-dependent manner. Hence, we only used these inhibitors to assess the ICD hallmarks (Fig. 3B-F). Moreover, we 
A
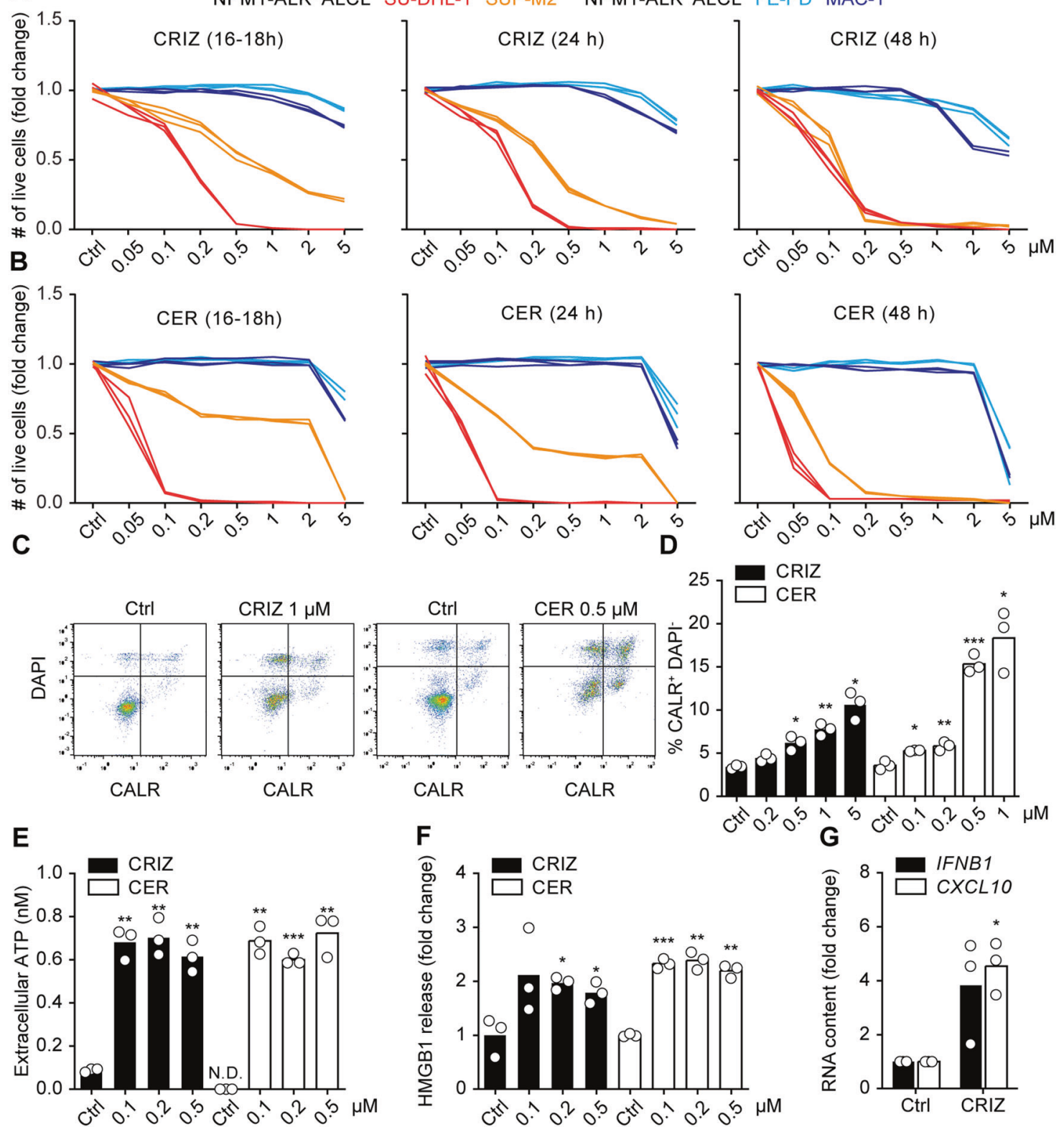

Fig. 1 Crizotinib- and ceritinib-induced immunogenic cell death. Human NPM1-ALK-positive (NPM1-ALK ${ }^{+}$) SU-DHL-1 and SUP-M2 cells and the NPM1-ALK-negative (NPM1-ALK) FE-PD and MAC-1 cells were treated with increasing concentrations of crizotinib (CRIZ) (A) or ceritinib (CER) (B) for $16-18,24$, or $48 \mathrm{~h}$. Cell death was evaluated using the mitochondrial transmembrane potential-sensible dye 3,3'dihexyloxacarbocyanine iodide $\left(\operatorname{DiOC}_{6}(3)\right)$ and 4',6-diamidino-2-phenylindole (DAPI). The number of live cells $\left(\mathrm{DiOC}_{6}(3)^{+} \mathrm{DAPI}^{-}\right)$normalized to vehicle control is represented for each replicate $(n=3)(\mathbf{A}, \mathbf{B})$. NPM1-ALK ${ }^{+}$SU-DHL-1 cells were treated with CRIZ or CER at the indicated concentrations, for $6 \mathrm{~h}$, and calreticulin (CALR) exposed on the cell surface was quantified by flow cytometry using an indirect immunofluorescence staining. DAPI was used to exclude permeabilized cells. A representative gating strategy is shown in $\mathbf{C}$, and the percentage of CALR ${ }^{+}$DAPI $^{-}$cells is depicted in $\mathbf{D}(n=3)$. NPM1-ALK ${ }^{+}$SU-DHL-1 cells were treated with CRIZ or CER for $24 \mathrm{~h}$ and ATP secreted in the extracellular milieu was quantified using a luciferase-dependent assay. Individual values are depicted in E $(n=3)$. NPM1-ALK ${ }^{+}$SU-DHL-1 cells were treated with CRIZ or CER for $48 \mathrm{~h}$ and high mobility group box 1 (HMGB1) was quantified in the supernatant using a specific ELISA. Fold increase for each replicate is shown in $\mathbf{F}(n=3)$. One representative out of three independent experiments is shown $\mathbf{A}-\mathbf{F}$. NPM1-ALK ${ }^{+}$SUDHL-1 cells were treated with $0.1 \mu \mathrm{M}$ of CRIZ for 16-18 h. IFNB1 and CXCL10 upregulation was assessed by quantitative PCR using specific fluorescently labeled primer-probe sets. GAPDH was used as housekeeping gene. Fold changes of three independent experiments are shown (G). Statistical significance was calculated using the Student's $t$ test. ${ }^{*} p<0.05,{ }^{* *} p<0.01,{ }^{* * *} p<0.001$ vs. vehicle-treated cells (D-G). N.D. nondetectable.

chose concentrations that yielded comparable levels of cell death. Inhibition of $\mathrm{PI} 3 \mathrm{~K}, \mathrm{PI} 3 \mathrm{~K} / \mathrm{mTOR}$, or ERK $1 / 2$ activated the molecular pathways leading to CALR translocation to the plasma membrane surface (Fig. 3C, Fig. S4). In addition, BEZ235, BKM120, and
PD0325901 provoked HMGB1 and ATP accumulation in the extracellular milieu (Fig. 3D, E). We used an alternative method, quinacrine orange staining, to confirm ATP secretion. Quinacrine accumulates in ATP-rich intracellular vesicles. Thus, ATP secretion 
A

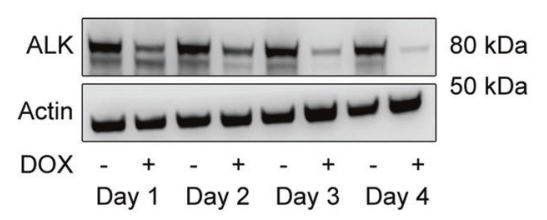

C

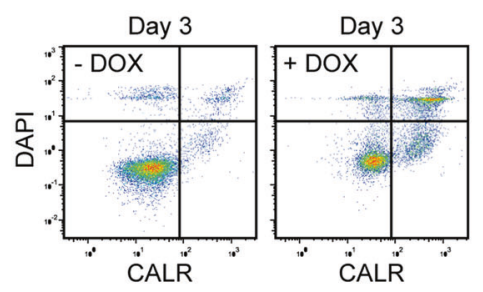

E

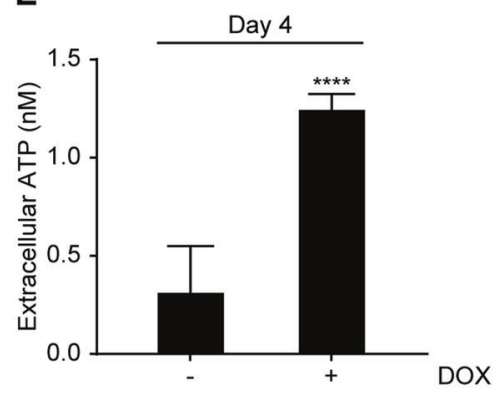

G

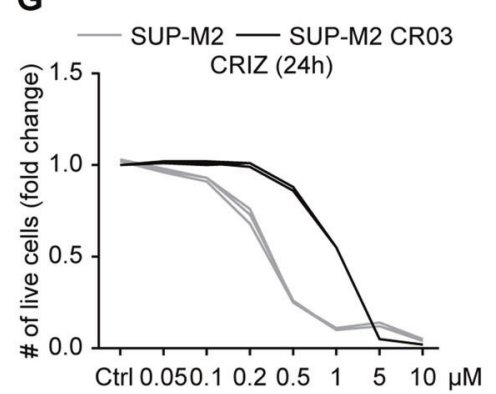

I

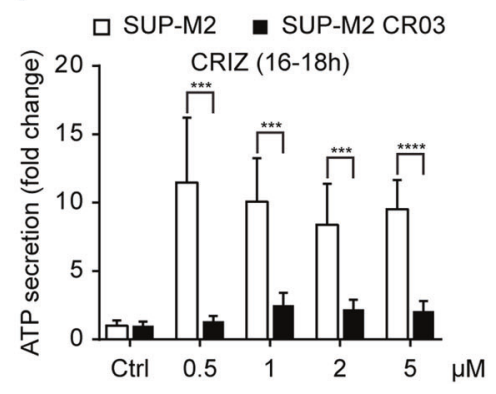

coincides with a decrease in quinacrine fluorescence intensity [43]. This method confirmed that inhibition of PI3K, mTOR, or ERK1/2 induced a reduction in cellular ATP content (Fig. 3F, Fig. S5). Among the distinct inhibitors, BKM120 (a PI3K inhibitor) appeared to be the most efficient in inducing signs of ICD (Fig.
B

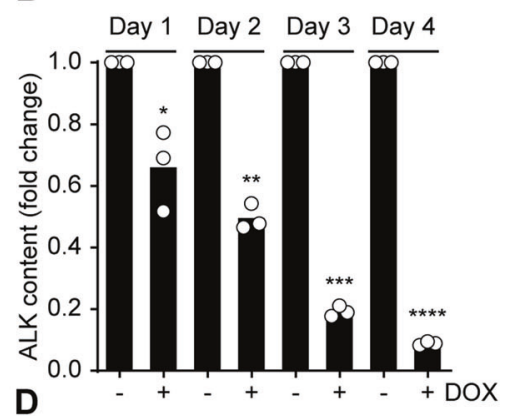

D
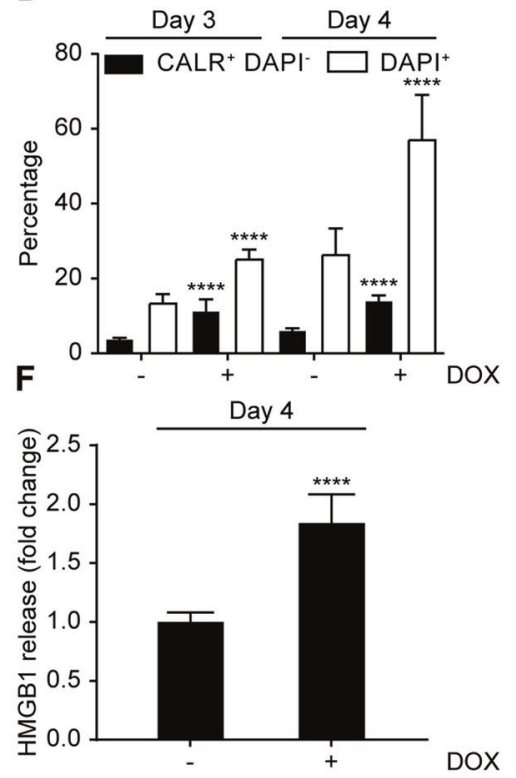

H

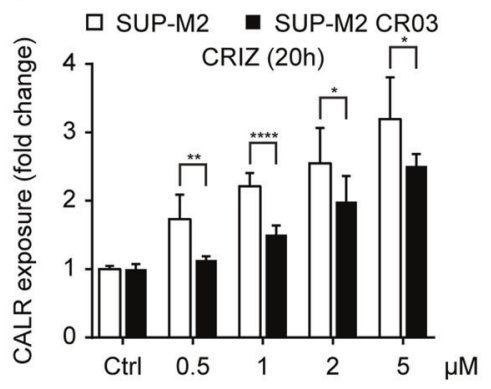

J

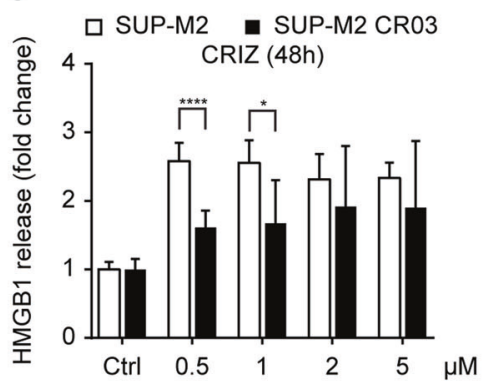

3C-F). Two additional PI3K inhibitors, BYL719 and XL147, also killed SU-DHL-1 and SUP-M2 cells and induced the hallmarks of ICD (Fig. S6).

In conclusion, it appears that inhibitors of several pathways operating downstream of ALK mimic the ICD-inducing effects of 
Fig. 2 Specific ALK inhibition induces immunogenic cell death. Immunogenic cell death of human NPM1-ALK ${ }^{+}$SU-DHL-1 TTA cell line expressing a doxycycline-inducible shRNA against ALK (A-F). shRNA induction was achieved after treatment with $1 \mu \mathrm{g} / \mathrm{mL}$ of doxycycline. ALK protein downregulation was confirmed by Western blot after 1, 2, 3, or 4 days of shRNA induction. Actin was used as loading control. Images are representative of one out of three experiments $(\mathbf{A})$. Relative quantification of three independent experiments is shown in B. SU-DHL-1 TTA cells were treated with $1 \mu \mathrm{g} / \mathrm{mL}$ of doxycycline for 3 or 4 days and cell death (\% $\mathrm{DAPI}^{+}$cells) as well as CALR exposed on the plasma membrane were quantified by flow cytometry. Gating strategy is shown in C and means \pm SD of 4 independent experiments $(n=12)$ are depicted in D. After 4 days of treatment, ATP secretion (E) and HMGB1 release (F) were quantified with a luciferase-based assay and ELISA, respectively. Means \pm SD of 3 independent experiments are shown $(n=9)$. Statistical significance was calculated using the Student's $t$ test. ${ }^{*} p<0.05,{ }^{* *} p<0.01,{ }^{* *} p<0.001,{ }^{* * *} p<0.0001$ vs. vehicle-treated cells (B, D-F). Evaluation of the immunogenic cell death hallmarks in human NPM1-ALK ${ }^{+}$cell line resistant to crizotinib (G-J). Crizotinib-resistant (SUP-M2 CR03) and parental (SUP-M2) cells were treated with increasing concentrations of crizotinib (CRIZ) for $24 \mathrm{~h}$ and cell death was evaluated using $\mathrm{DiOC}_{6}(3)$, which labels only mitochondria of live cells, and DAPI entering cells only after plasma membrane permeabilization. The number of live cells $\left(\mathrm{DiOC}_{6}(3)^{+} \mathrm{DAPI}^{-}\right)$normalized to vehicle controls is represented for each replicate $(n=3)(\mathbf{G})$. CALR translocated to the plasma membrane was quantified by immunofluorescence and flow cytometry after treatment with CRIZ for $20 \mathrm{~h}$. Fold increases were calculated using the median of fluorescent intensity (MFI) of DAPI cells (H). ATP (I) and HMGB1 (J) released after 16-18 or $48 \mathrm{~h}$ of treatment, respectively, were quantified using a luciferase-based assay or an ELISA test. Means of three independent experiments (each made in triplicates) \pm SD are shown. Statistical significance was calculated using the multiple Student's $t$ test $(n=9) ;{ }^{*} p<0.05,{ }^{* *} p<0.01,{ }^{* * *} p<0.001,{ }^{* * * *} p<0.0001(\mathbf{H}-\mathbf{J})$.

crizotinib, and among these pathways, $\mathrm{PI} 3 \mathrm{~K}$ stands out at as a particularly important ICD repressor.

\section{Immune-dependent effects of ALK-inhibitors in vivo}

Next, we characterized the immunogenicity of ALK inhibitors in vivo. For that purpose, we first validated the induction of surrogate ICD markers in a murine cell line, R80, generated from transgenic C57BL/6 mice expressing human NPM1-ALK. R80 cells showed signs of ICD after ALK inhibition by crizotinib or ceritinib (Fig. 4). Moreover, when cells were exposed to crizotinib or ceritinib and then co-cultured with bone marrow-derived dendritic cells (BMDCs), clear evidence was found that they were engulfed by BMDCs (Fig. 5A-C) and induced BMDC maturation (Fig. S7).

A standard in vivo assay for ICD consists in the subcutaneous injection of dying/dead cells into immunocompetent mice, followed by rechallenge with live tumor cells 1-2 weeks later into the opposite flank to interpret the reduction of tumor growth as an indication of successful anticancer vaccination [44]. R80 cells were treated with ceritinib in vitro, washed, and then injected subcutaneously (s.c.) into immunocompetent syngeneic C57BL/6. After two weeks, these animals were re-challenged with live R80 injected into the opposite flank (Fig. 5D). Mice vaccinated with ceritinib-treated R80 cells exhibited a delay in tumor growth when compared to non-vaccinated mice (Fig. 5E, S8). These results suggest that R80 cells are indeed immunogenic upon ALK inhibition with ceritinib.

Next, we established subcutaneous R80 lymphomas on immunocompetent C57BL/6 mice or immunodeficient Foxn $1^{\text {nu }}$ mice (which are athymic and hence lack thymus-derived $T$ lymphocytes) and treated them with ceritinib or vehicle-only (Fig. 6A). Of note, in this system, vehicle-treated R80 lymphomas developed more quickly on immunodeficient than on immunocompetent mice, suggesting that they are under natural (therapyindependent) immunosurveillance. Ceritinib-treated tumors regressed in a transient fashion, both in immunocompetent and in immunodeficient hosts (Fig. 6B, C). After approximately 10 days, the majority of tumors grew back, but 3 out of 11 mice were permanently ( $\geq 60$ days) cured in immunocompetent hosts (Fig. $6 B, C, E)$. This is in sharp contrast with the effects of ceritinib observed against R80 lymphomas growing on immunodeficient mice, which all relapsed rather quickly in less than 10 days (Fig. 6B, $C, E)$. These T-lymphocyte-dependent ceritinib effects also influenced the survival of R80 lymphoma-bearing mice. In immunocompetent R80 lymphoma-bearing mice, ceritinib extended median survival by $\sim 20$ days, while this interval was reduced to $\sim 10$ days in immunodeficient mice (Fig. 6D). When cured mice (which were all immunocompetent) were reinoculated with R80 tumor cells, 2 out of 3 exhibited a long- term protection. In contrast, naïve mice always (in this experiment 4 out of 4 mice) allowed for R80 lymphoma cells to generate subcutaneous tumors. Antigenically unrelated EL4 lymphoma cells indistinguishably formed tumors in naïve mice and animals ridden from R80 lymphomas (Fig. 6F). Of note, repeated injection of a PD1-blocking antibody failed to significantly improve tumor growth reduction, but tended to enhance the frequency of long-term $(\geq$ 60 days) cures, which increased from 3 out of 9 cases in R80 lymphoma bearing $\mathrm{C} 57 \mathrm{BL} / 6$ mice treated with ceritinib plus isotype control antibody to 5 out of 9 cases in mice treated with ceritinib plus anti-PD-1 antibody (Fig. 7).

We conclude from these results that ALK inhibition by ceritinib can result in therapeutically relevant ICD induction.

\section{DISCUSSION}

Immunogenic cell death (ICD) has mostly been characterized in the context of cytotoxic agents that non-specifically target general cellular functions such as DNA-to-RNA transcription or microtubular polymerization. Thus, historically, anthracyclines and oxaliplatin have been listed among the first ICD inducers $[13,45]$. The most recent clinically approved ICD inducers are lurbinectedin, an inhibitor of transcription that was FDA-approved for the treatment of small-cell lung cancer in June 2020 [46], as well as an anti-BCMA antibody conjugated to a microtubular poison (belantamab mafodotin) that was FDA-approved in August 2020 for the treatment of relapsed or refractory multiple myeloma [47]. Our recent work suggests that specific tyrosine kinase inhibitors (TKIs) may have ICD-inducing effects as well. Indeed, a screening initially performed on osteosarcoma U2OS cells revealed that several TKIs, including crizotinib, used at concentration $\geq 10 \mu \mathrm{M}$ could elicit the stigmata of ICD in vitro. Since U2OS cells lack constitutive activation of ALK, this effect is clearly offtarget and may be explained by the simultaneous inhibition of several tyrosine kinases by high crizotinib doses. Nevertheless, these observations created the precedent that TKls can induce ICD, though through off-target effects [35].

In the present paper, we characterized on-target effects of crizotinib by specifically evaluating its effects on ALK-positive anaplastic large cell lymphoma $\left(\mathrm{ALK}^{+} \mathrm{ALCL}\right)$ (which depends on ALK as a major oncogenic and trophic factor). Specificity was assured by several parallel strategies, namely by (i) reducing the concentration of crizotinib to lower doses $(\leq 5 \mu \mathrm{M})$ that do not affect ALK-independent lymphomas, (ii) replacing crizotinib by ceritinib, which has a higher potency and specificity for ALK [48], (iii) assuring that genetic inhibition (inducible knockdown) of ALK mirrored the effects of its pharmacological interference, (iv) evaluating crizotinib effects on cells that had become resistant to this inhibitor due to mutation of ALK kinase domain. Of note, 
A

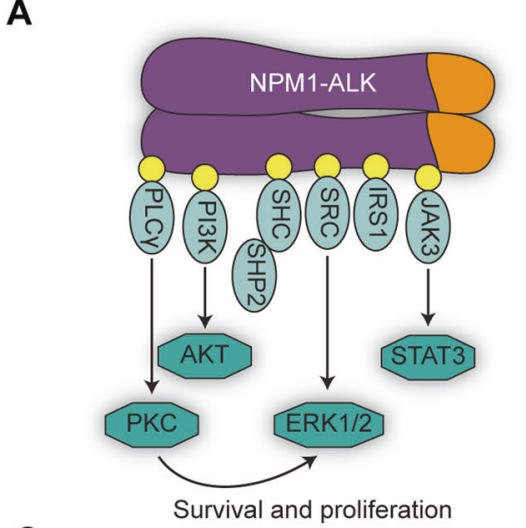

C

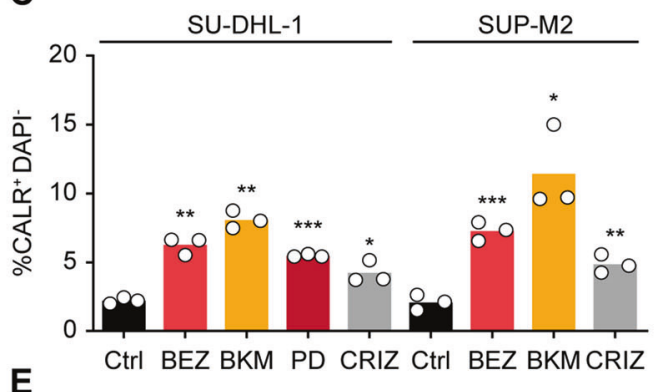

E

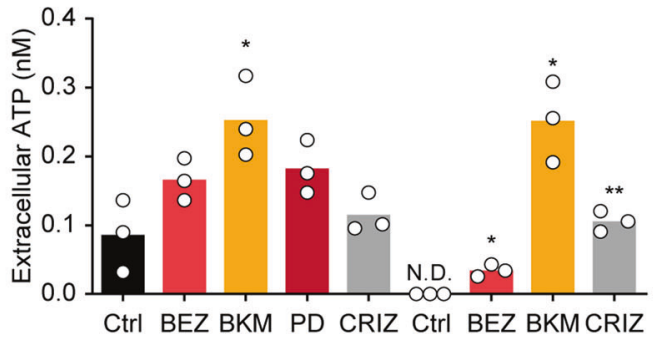

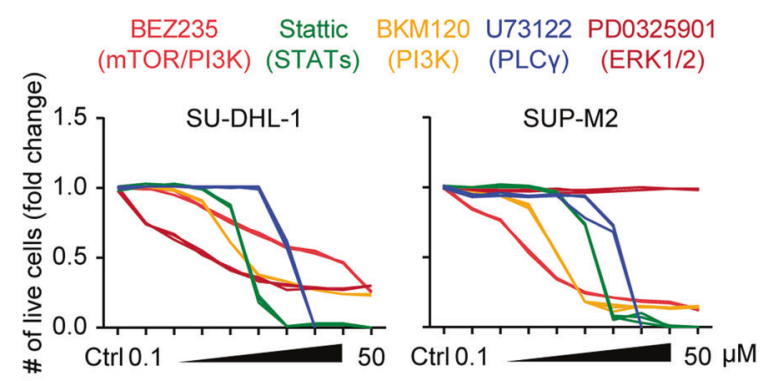
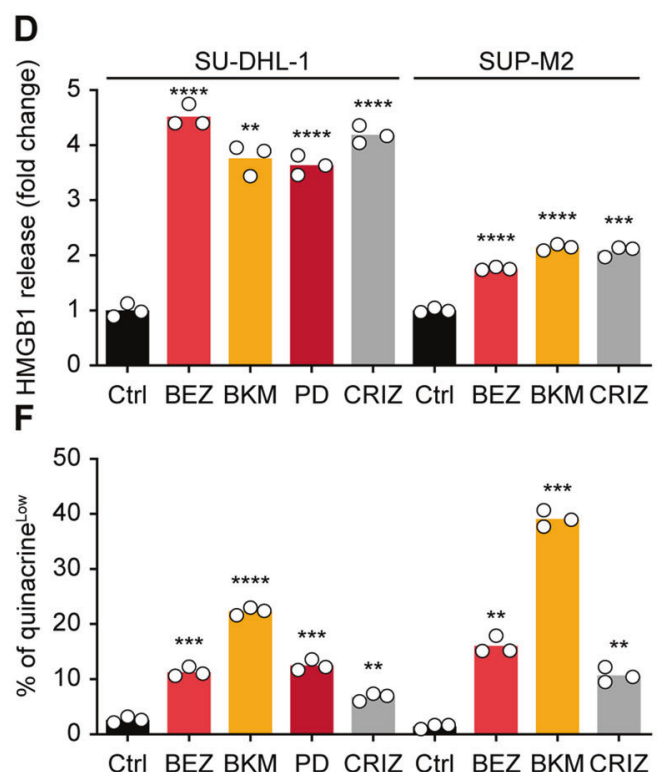

Fig. 3 Dissection of ALK downstream pathways inducing immunogenic cell death. Scheme of ALK downstream signaling pathways (A). Human NPM1-ALK ${ }^{+}$SU-DHL-1 and SUP-M2 cells were treated with PI3K, PI3K/mTOR, ERK1/2, PLCY, and STATs inhibitors (BEZ235, BKM120, PD0325901, U73122, and stattic, respectively) at $0.1,0.2,0.5,1,2,5,10,20$, and $50 \mu \mathrm{M}$. Cell death was evaluated using DiOC 6 (3) and DAPI after $24 \mathrm{~h}$. The number of live cells $\left(\operatorname{DiOC}_{6}(3)^{+} \mathrm{DAPI}^{-}\right)$, normalized to vehicle control, is shown for each replicate $(n=3)(\mathbf{B})$. NPM1-ALK ${ }^{+}$SU-DHL-1 and SUP-M2 cells were treated with 2 or $5 \mu \mathrm{M}$ of BEZ235 (BEZ); $2 \mu \mathrm{M}$ of BKM120 (BKM); 1 or $2 \mu \mathrm{M}$ of PD0325901 (PD); 0.1 or $0.5 \mu \mathrm{M}$ of crizotinib (CRIZ). After 16-18 h (SU-DHL-1) or $24 \mathrm{~h}$ (SUP-M2) CALR was indirectly stained on the plasma membrane and percentage of CALR ${ }^{+} \mathrm{DAPI}^{-}$cells was quantified by flow cytometry (C). ATP (E) and HMGB1 (D) were quantified in the extracellular milieu of cells treated for 16-18 $\mathrm{h}(\mathrm{E})$ or $24 \mathrm{~h}$ (D), using a luciferase-dependent assay or an ELISA, respectively. The propensity of quinacrine to accumulate in ATP-rich vesicles was exploited to quantify the intracellular content of ATP by flow cytometry after $16-18 \mathrm{~h}$ of treatment. DAPI was employed as exclusion dye for permeabilized cells. Percentages of quinacrine ${ }^{\text {low }}$ cells within DAPI population are displayed in $\mathbf{F}$. Individual replicates are shown $(n=3)$ from one out of three independent experiments. Statistical significance was calculated using the Student's $t$ test. ${ }^{*} p<0.05,{ }^{* *} p<0.01,{ }^{* * *} p<0.001$, ${ }_{* * * *} p<0.0001$ vs. vehicle-treated cells (B-F). N.D. non-detectable.

results obtained by these approaches plead in favor of specific ALK inhibition inducing ICD. Both human and mouse $\mathrm{ALK}^{+} \mathrm{ALCL}$ cells displayed the hallmarks of ICD (CALR exposure, ATP release, HMGB1 exodus). Moreover, vaccination of mice with ceritinibtreated ALK-dependent ALCL was able to restrain the progression of the same lymphoma inoculated 2 weeks later.

In vivo treatment of $\mathrm{ALK}^{+} \mathrm{ALCL}$ bearing mice with ceritinib showed that ALK inhibition acted in two complementary ways. First, ceritinib clearly mediated a therapeutic effect that was independent of adaptive T-cell responses and hence significantly reduced the volume of established lymphomas irrespective of the host immune status. Second, tumor shrinkage was followed by relapse, which occurred more frequently $(p<0.05$, Chi square test) in immunodeficient (9 out of 9) mice (Fig. 6) than in immunocompetent hosts (14 out of 20, Figs. 6 and 7), especially when combined with PD-1 blockade (5 out of 9, Fig. 7). Hence, $30 \%$ of immunocompetent mice could be cured from $\mathrm{ALK}^{+} \mathrm{ALCL}$ by ceritinib (Figs. 6 and 7), and addition of PD-1 blockade (Fig. 7) lead to an increase of this percentage to $55 \%(p<0.05$, Chi square test for data pooled from Figs. 6 and 7). These results strongly indicate that the cell-autonomous effects of ALK inhibitors are complemented by an additional, immune-mediated mechanism of tumor control.

The last decades witnessed great progresses in the treatment of hematological cancers, with a transition from chemotherapeutic regimes hitting all proliferating cells to drugs targeting tumorspecific survival pathways, such as tyrosine kinase inhibitors. Although this shift has led to a spectacular amelioration of cure rates, there is still room for improvement. Recent developments plead in favor of the adoption of immunological concepts to blood cancers. For example, PD-1 blockade showed great clinical success in relapsed or refractory Hodgkin lymphoma [49, 50]. Another promising immunotherapeutic approach is vaccination. In chronic myeloid leukemia patients, remissions have been achieved after vaccination with BCR-ABL-derived peptides [51]. Concerning $\mathrm{ALK}^{+}$ $A L C L$, several studies unequivocally demonstrated that patients 
A
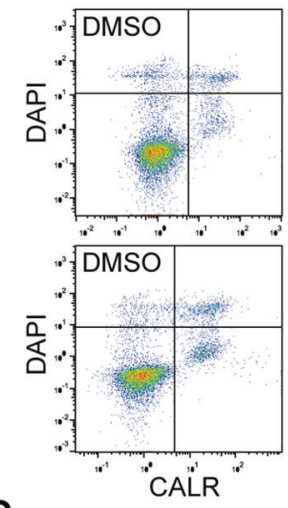

C
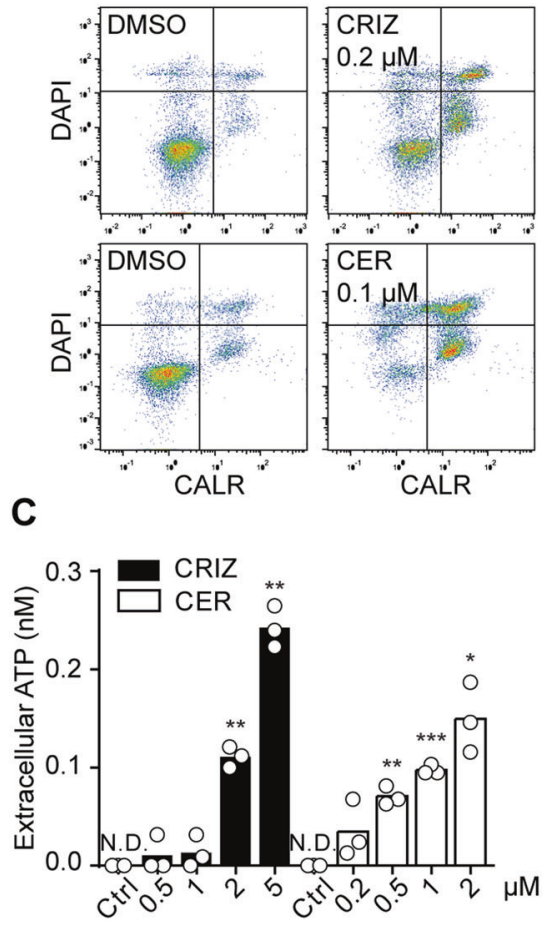

B

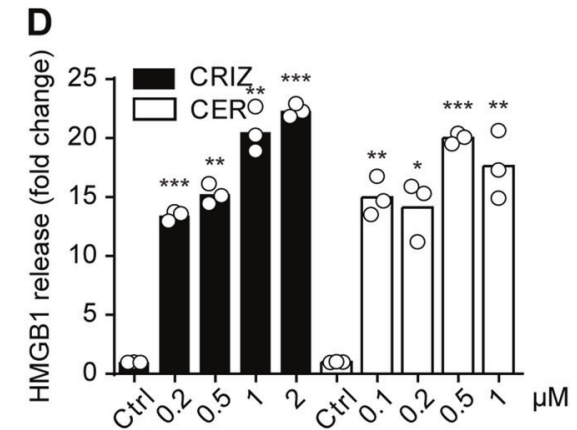

Fig. 4 Immunogenic cell death of murine ALK-positive cells. Murine NPM1-ALK ${ }^{+}$R80 cells were treated with increasing concentrations of crizotinib (CRIZ) or ceritinib (CER) for $6 \mathrm{~h}$. Twenty hours later, exposed CALR was quantified on the surface of DAPI cells by flow cytometry using an indirect fluorescent staining. Representative dot plots are shown in A and percentage of CALR ${ }^{+}$DAPI $^{-}$in B. ATP (C) or HMGB1 (D) released in the extracellular milieu of murine NPM1-ALK ${ }^{+}$R80 cells, treated with CRIZ or CER, were assessed using a luciferase-based assay or an ELISA after 6 or $24 \mathrm{~h}$, respectively. Values of one representative experiment out of three are shown $(n=3)(\mathbf{A}-\mathbf{D})$. Statistical significance was calculated using the Student's $t$ test. ${ }^{*} p<0.05,{ }^{* *} p<0.01,{ }^{* * *} p<0.001,{ }^{* * * *} p<0.0001$ vs. vehicle-treated cells. N.D. non-detectable.

develop a specific antitumor immune response. Pulford and collaborators showed the presence of autoantibodies against NPM1-ALK in ALCL patients [52], and higher antibody titers were correlated with improved overall and progression-free survival, as well as reduced relapse rates [53]. Whether such anti- NPM1-ALK antibodies are mere signs of an immune response or true immune effectors, however, has not been clarified, and ICD-related immune responses are mostly mediated by $\mathrm{CD}^{+}$(not $\mathrm{CD} 4^{+}$) T cells $[54,55]$. Indeed, ALK-specific $\mathrm{CD}^{+} \mathrm{T}$ cells occur naturally in healthy subjects and ALCL patients. However, the former show a naïve phenotype, while the latter show an effector or memory phenotype, suggesting a relatively recent activation [56]. Altogether, these observations indicate that immunotherapy might be a therapeutic option for $\mathrm{ALK}^{+} \mathrm{ALCL}$. Indeed, two case reports demonstrated that, in relapsed $\mathrm{ALK}^{+} \mathrm{ALCL}$ patients, $\mathrm{PD}-1$ blockade led to complete and long-lasting remissions [57, 58]. In addition, preclinical data demonstrated that vaccination with DNA plasmids encoding for the cytoplasmic domain of ALK successfully prevented the occurrence of systemic $\mathrm{ALK}^{+} \mathrm{ALCL}$ [59].

The present work demonstrates that TKIs designed to inhibit ALK oncogenic kinase induce hallmarks of ICD in ALK-dependent tumors, through a rigorous on-target effect. These effects are also reflected by immune responses against ALK-induced anti-lymphoma in a preclinical model. Hence, the successful treatment of ALCL most likely relies, at least in part, on improved immunosurveillance. Future studies must explore the clinical utility of combining ALK inhibitors with immunotherapeutic strategies for the definitive cure of $A L K^{+} \mathrm{ALCL}$.

\section{MATERIAL AND METHODS}

\section{Cell lines and culture conditions}

Human NPM1-ALK-positive (NPM1-ALK ${ }^{+}$) anaplastic large cell lymphoma (ALCL) SU-DHL-1 cell line was purchased from the German Collection of
Microorganisms and Cell Cultures (DSMZ, Braunschweig, Germany). Human NPM1-ALK ${ }^{+}$ALCL SUP-M2 and NPM1-ALK-negative (NPM1-ALK) ALCL MAC-1 and FE-PD cell lines were kindly provided by Dr. Meggetto (Centre de Recherches en Cancérologie de Toulouse, France); human NPM1-ALK ${ }^{+}$ ALCL SUP-M2 cell line crizotinib-resistant (SUP-M2CR03) [40] by Dr. Ceccon and Prof. Gambacorti-Passerini (Università degli Studi di Milano-Bicocca, Italy) and human NPM1-ALK ${ }^{+}$ALCL SU-DHL-1 TTA [39] cell line by Dr. Ducray (University of Cambridge, United Kingdom). Prof. Chiarle (Boston Children's Hospital, Massachusetts, USA) and Dr. Poggio (Uniklinik Freiburg, Germany) provided the murine NPM1-ALK ${ }^{+}$cell line R80. Cells were cultured in RPMI 1640 supplemented with 100 units $/ \mathrm{mL}$ of penicillin, $100 \mu \mathrm{g} / \mathrm{mL}$ of streptomycin (Pen/Strep) and $10 \%$ fetal bovine serum (FBS) or $10 \%$ tetracycline-free FBS (PAN-Biotech, Aidenbach, Germany) (for SUDHL-1 TTA cell line). All cell lines were cultured at $37^{\circ} \mathrm{C}$ and $5 \% \mathrm{CO}_{2}$ and routinely checked for mycoplasma contamination. All media and supplements were purchased from Gibco (Waltham, Massachusetts, USA).

\section{Cell treatments}

ALCL cells were harvested, seeded at $2.5-5 \times 10^{5} / \mathrm{mL}$ and concurrently treated with pharmacological inhibitors. Inhibitors used throughout this study were: crizotinib (CRIZ; Sigma-Aldrich, St. Louis, Missouri, USA), ceritinib (CER; Selleck Chemicals, Houston, Texas, USA), BEZ235 (BEZ; Selleck Chemicals), BKM120 (BKM; Selleck Chemicals), PD0325901 (PD; Sigma-Aldrich), stattic (Selleck Chemicals), U73122 (Tocris, Bristol, UK), BYL719 (BYL; Selleck Chemicals), XL147 (XL; Selleck Chemicals), and Q-VDOPh (Calbiochem, San Diego, California, USA). Mitoxantrone (MTX) was purchased from Sigma-Aldrich. SU-DHL-1 TTA were treated with $1 \mu \mathrm{g} / \mathrm{mL}$ of doxycycline (Sigma-Aldrich).

\section{Immunogenic cell death assays}

Cell death analysis. Cell death was assessed by flow cytometry employing the following fluorescent dyes: 3,3-dihexyloxacarbocyanine iodide ( $\mathrm{DiOC}_{6}(3), 20 \mathrm{nM}$; Thermo Fisher Scientific, Waltham, Massachusetts, USA) selective for mitochondria of live cells; 4,6-diamidino-2-phenylindole (DAPI; $1 \mu \mathrm{g} / \mathrm{mL}$, Invitrogen, Carlsbad, California, USA) incorporated by dead 
A

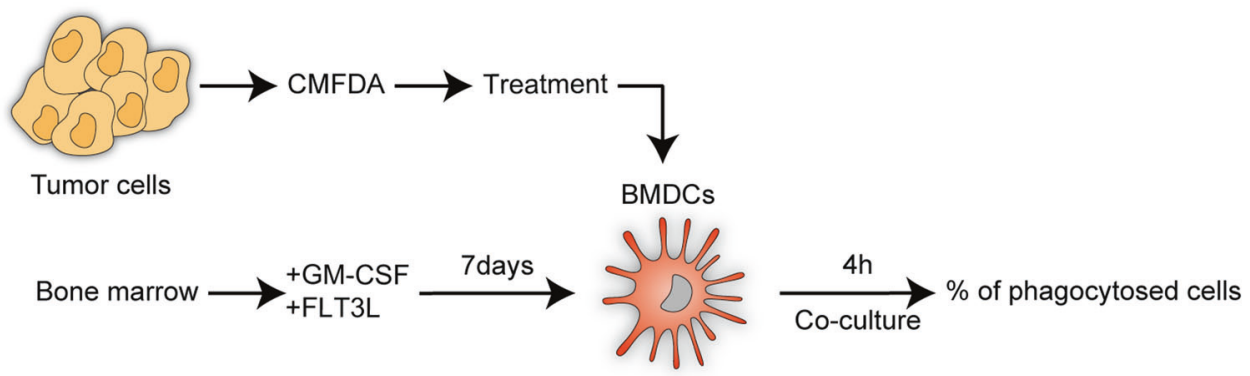

B
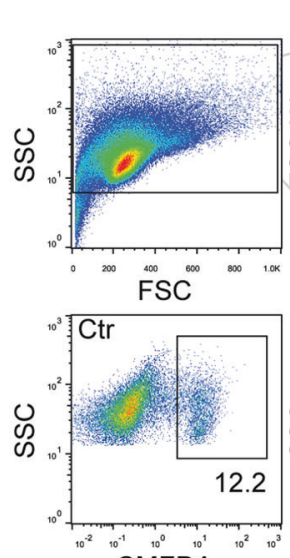

CMFDA
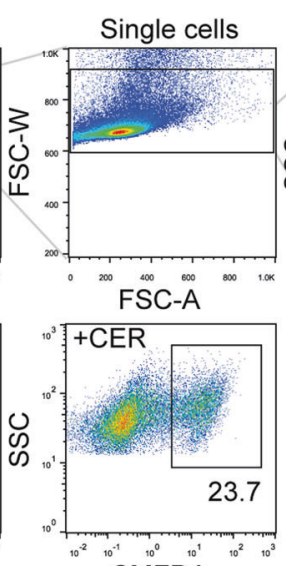

CMFDA

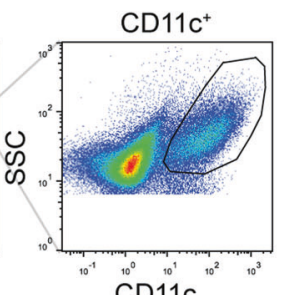

CD11c

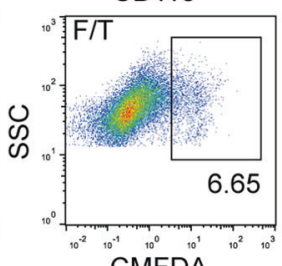

C

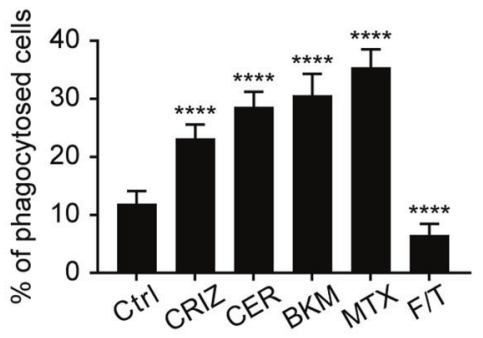

D

CER-treated cells $\bullet$ or vehicle $\bullet$ s.c.

Live cells $\bullet$ s.c.

Tumor growth monitoring
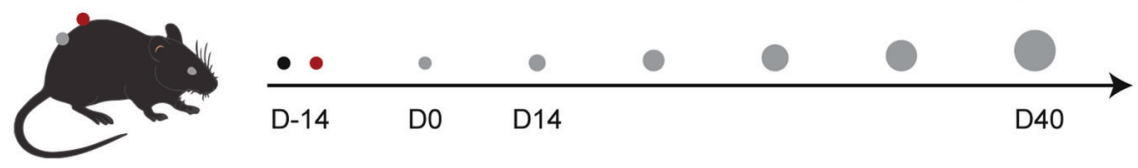

$\mathbf{E}$

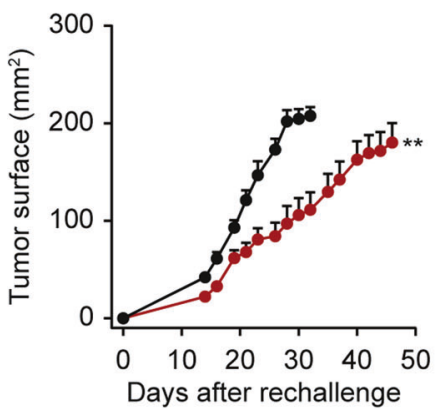

- Vehicle - CER-treated cells
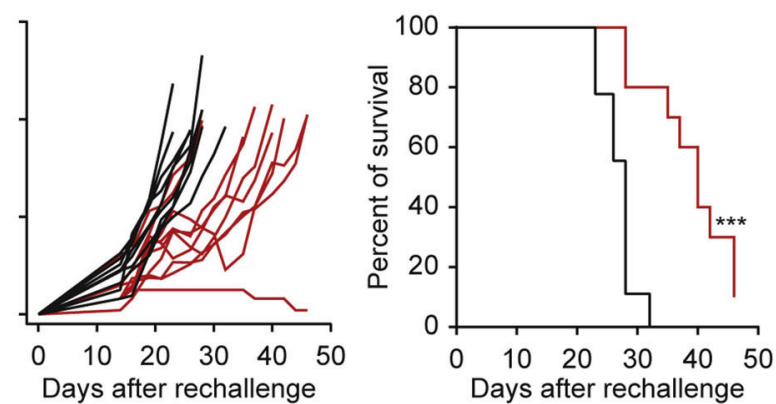

cells after cell membrane rupture. After treatment, cells were incubated with $\mathrm{DiOC}_{6}(3)$ and DAPI diluted in medium, for $30 \mathrm{~min}$ at $37^{\circ} \mathrm{C} / 5 \% \mathrm{CO}_{2}$ $[60,61]$ and analyzed by means of a MACSQuant flow cytometer (Miltenyi Biotec, Bergisch Gladbach, Germany). Data were analyzed with Flowjo software (Ashland, Oregon, USA).

Calreticulin (CALR) exposure. Following treatments, cells were transferred to a 96-well plate and washed twice with $150 \mu \mathrm{l} /$ well of cold $\left(4^{\circ} \mathrm{C}\right) \mathrm{PBS}$. Then, they were resuspended in $50 \mu \mathrm{l} /$ well of anti-CALR antibody (Abcam, Cambridge, UK) diluted in PBS supplemented with $1 \%$ bovine serum albumin (BSA) and incubated for $45 \mathrm{~min}$ on ice. Afterwards, cells were washed twice with $150 \mu \mathrm{l} /$ well of cold PBS and resuspended in $50 \mu \mathrm{l} /$ well of goat anti-rabbit lgG-Alexa Fluor 488 or -Alexa Fluor 647 (Invitrogen) diluted in $\mathrm{PBS} / 1 \% \mathrm{BSA}$. After $30 \mathrm{~min}$ of incubation on ice and two additional washing steps, cells were resuspended in $120 \mu \mathrm{l} /$ well of cold PBS supplemented with DAPI at $1 \mu \mathrm{g} / \mathrm{mL}$ [61, 62]. Cells were analyzed by means of a MACSQuant flow cytometer and data were analyzed with FlowJo software.

Adenosine triphosphate (ATP) secretion. ATP secreted in the extracellular milieu was quantified using the ENLITEN ATP assay (Promega, Madison, Wisconsin, USA). Cell supernatants were collected and cell debris removed 
Fig. 5 ALK inhibition activates the immune system. As illustrated in the phagocytosis assay scheme (A), murine tumor cells were, first, stained with the green cell tracker (CMFDA), then, treated with different drugs, while bone marrow-derived dendritic cells (BMDCs) were isolated from syngeneic mice and differentiated in vitro. After co-culture, the percentages of phagocytized cells were determined by flow cytometry. B Murine NPM1-ALK ${ }^{+}$R80 cells were treated with $0.2 \mu \mathrm{M}$ of crizotinib (CRIZ) or ceritinib (CER), $2 \mu \mathrm{M}$ of BKM120 (BKM), $1 \mu \mathrm{M}$ of mitoxantrone (MTX) for 16-18 h or subjected to one cycle of freeze-thawing (F/T) and co-cultured with BMDCs for $4 \mathrm{~h}$. Co-culture was stained

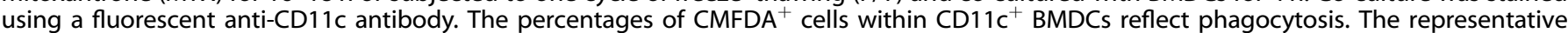
gating strategy is shown in B. C Means \pm SD of three independent experiments each performed in triplicates $(n=9) ;{ }^{* * * *} p<0.0001($ Student's $t$ test) (C). Scheme of vaccination experiment (D). Murine tumor cells were treated in vitro to reach $50-70 \%$ of mortality before being injected into the left flank of syngeneic mice. Two weeks later, mice were challenged with live cells into the opposite flank and tumor appearance and growth were monitored. Five million of NPM1-ALK ${ }^{+}$R80 cells, previously treated for $24 \mathrm{~h}$ with $0.5 \mu \mathrm{M}$ of CER, were injected into the left flank of C57BL/6 mice. After two weeks, mice were challenged with $1 \times 10^{6}$ of live R80 cells into the opposite flank. Tumor surface in function of time is represented as mean \pm SEM of mice belonging to the same group or for each mouse (E). Survival is also represented in $\mathbf{E}$. Vehicle $n=9$ and CER $n=10$. Comparison between tumor growth curves was assessed using a type II ANOVA test, while the statistical significance of survival data was calculated using the Log-rank test. ${ }^{* *} p<0.01,{ }^{* * *} p<0.001$.

by centrifugation at $1000 \mathrm{~g}$ for $5 \mathrm{~min}$. Then, $20 \mu \mathrm{l}$ of supernatants were transferred to an opaque-walled 96-well plate together with ATP diluted at $10^{-7} \mathrm{M}, 10^{-8} \mathrm{M}, 10^{-9} \mathrm{M}, 10^{-10} \mathrm{M}$, and $10^{-11} \mathrm{M}$ as standards and water (blank). Afterwards, $100 \mu \mathrm{l}$ of rLuciferase/Luciferin (rL/L) reagent were added to supernatants and standards and emitted bioluminescence was measured with a plate reading luminometer (Victor, PerkinElmer, Waltham, Massachusetts, USA). ATP concentrations were calculated using fourparameter logistics.

High-Mobility Group Box 1 (HMGB1) release. HMGB1 released in the extracellular environment after treatment was quantified using a sandwich ELISA (IBL International, Hamburg, Germany) following manufacturer's instructions. Briefly, supernatant was collected and cell debris were removed by centrifugation at $1000 \mathrm{~g}$ for $5 \mathrm{~min}$. Then, $10 \mu \mathrm{l}$ of supernatants or HMGB1 standards were added to the microtiter plate together with $100 \mu \mathrm{l} /$ well of "diluent buffer". After $20-24 \mathrm{~h}$ of incubation at $37^{\circ} \mathrm{C}$ and five washing steps with $400 \mu \mathrm{l} /$ well of "washing buffer", $100 \mu \mathrm{l} /$ well of "enzyme conjugate" were added and the plate was incubated for $2 \mathrm{~h}$ at room temperature. After five additional washing steps, $100 \mu \mathrm{l} /$ well of "color solution" were added and incubated for $30 \mathrm{~min}$ at room temperature. Color development was stopped with $100 \mu \mathrm{l} /$ well of "stop solution" and absorbance at $450 \mathrm{~nm}$ was measured using a spectrophotometer (Victor, PerkinElmer). Absorbance values of each standard were plotted against their known concentration and unknown HMGB1 concentrations were calculated using four-parameter logistics $[63,64]$.

Interferon beta 1 (IFNB1) and C-X-C motif chemokine 10 (CXCL10) upregulation. Following treatment, total RNA was extracted using the Rneasy plus mini kit (Qiagen, Hilden, Germany) following manufacturer's instruction. Genomic DNA was digested during RNA purification using the RNase-Free DNase Set (Qiagen) according to manufacturer's guidance. Next, total RNA was reverse transcribed to CDNA using SuperScript ${ }^{\mathrm{TM}}$ IV VILO $^{\text {m }}$ Master Mix (Thermo Fisher Scientific). Briefly, 1 to $2.5 \mu \mathrm{g}$ of RNA were diluted in $16 \mu \mathrm{l}$ of nuclease-free water and $4 \mu \mathrm{l}$ of SuperScript ${ }^{\mathrm{TM}} \mathrm{IV}$ $\mathrm{VILO}^{\mathrm{TM}}$ Master Mix were added. Reverse transcription was performed under the following conditions: primer annealing at $25^{\circ} \mathrm{C}$ for $10 \mathrm{~min}$, reverse transcription at $50^{\circ} \mathrm{C}$ for $10 \mathrm{~min}$, and heat inactivation at $85^{\circ} \mathrm{C}$ for $5 \mathrm{~min}$. Thereafter, IFNB1, CXCL10, or GAPDH were amplified using specific TaqMan Gene Expression assays (Thermo Fisher Scientific) using the TaqMan Fast Advanced Master Mix (Thermo Fisher Scientific) on the StepOnePlus RealTime PCR System (Applied Biosystems, Waltham, Massachusetts, USA). Running conditions were $50^{\circ} \mathrm{C}$ for $2 \mathrm{~min}, 95^{\circ} \mathrm{C}$ for $2 \mathrm{~min}$ followed by 40 cycle of target gene amplification $\left(95^{\circ} \mathrm{C}\right.$ for $1 \mathrm{~s}$ and $60^{\circ} \mathrm{C}$ for $20 \mathrm{~s}$ ). Finally, threshold cycle $\left(C_{t}\right)$ values of genes of interest were subtracted to $C_{t}$ values of the housekeeping gene, GAPDH, generating $\triangle \mathrm{cts}$; fold change of expression between crizotinib-treated and vehicle-treated samples was calculated using the formula: $2^{(-\Delta \Delta C \mathrm{t})}$.

Quinacrine staining. Cells were transferred to a 96-well plate and washed twice with $150 \mu \mathrm{l} /$ well of "Krebs solution" $(125 \mathrm{mM} \mathrm{NaCl}, 5 \mathrm{mM} \mathrm{KCl}, 1 \mathrm{mM}$ $\mathrm{MgSO}_{4}, 0.7 \mathrm{mM} \mathrm{KH_{2 }} \mathrm{PO}_{4}, 2 \mathrm{mM} \mathrm{CaCl}, 6 \mathrm{mM}$ Glucose, $25 \mathrm{mM}$ 4-(2hydroxyethyl)-1-piperazineethanesulfonic acid or HEPES, $\mathrm{H}_{2} \mathrm{O}$ ). Afterwards, they were resuspended in $100 \mu \mathrm{l} /$ well of quinacrine (Sigma-Aldrich) diluted in "Krebs solution" at $2 \mu \mathrm{M}$ and incubated for $30 \mathrm{~min}$ at $37^{\circ} \mathrm{C} / 5 \%$ $\mathrm{CO}_{2}$. Then, after two more washing steps, cells were resuspended in $120 \mu \mathrm{l} /$ well of "Krebs solution" supplemented with $1 \mu \mathrm{g} / \mathrm{mL}$ of DAPI and cells were analyzed by means of a MACSQuant flow cytometer [43, 65]. Data were analyzed with FlowJo software.

\section{Immunoblotting}

After treatment, cells were lysed in $150 \mu \mathrm{l}$ of RIPA buffer (Sigma-Aldrich) for $45 \mathrm{~min}$ on ice. After removing cell debris, by centrifugation at $14,000 \mathrm{rpm}$ for $15 \mathrm{~min}$, protein extracts were loaded onto $4-12 \%$ polyacrylamide gel (Invitrogen) and then transferred to a $0.2 \mu \mathrm{m}$ nitrocellulose membrane (Bio-Rad, Hercules, California, USA). Unspecific binding sites were saturated incubating membranes with Tris-buffered saline (TBS) supplemented with $0.05 \%$ Tween 20 (TBST) and 5\% non-fat powdered milk or BSA. Thereafter, membranes were incubated with primary antibodies diluted in TBST $/ 5 \%$ BSA for $16-18 \mathrm{~h}$ at $4{ }^{\circ} \mathrm{C}$. Antibody binding was revealed using a suitable secondary antibody coupled to horseradish peroxidase conjugates (HRP) (Southern Biotech, Birmingham, Alabama, USA) diluted in TBST/5\% milk and incubated for $1 \mathrm{~h}$, followed by chemiluminescence-based detection (Amersham, Little Chalfont, UK). Images were acquired using the ImageQuant LAS 4000 software-assisted imager (GE Healthcare, Chicago, Illinois, USA). Quantification was performed with ImageJ software.

\section{Antibodies}

Anti-CALR (ab2907) antibody was purchased from Abcam. Anti-ALK (3633) -phospho-Akt (9271), -total Akt (9272), -caspase-3 (9662), -caspase-8 (9746), -phospho-elF2a (9721), -total elF2a (9722) -phospho- ERK1/2 (4370), -total ERK1/2 (4695) were purchased from Cell Signaling Technology (Danvers, Massachusetts, USA). Anti-CD11c coupled to PE-Vio770 (clone N418) was purchased from Miltenyi Biotec, whereas anti-CD86-Alexa Fluor 647 (clone GL-1) and anti-la/le-APC (cloneM5/114.15.2) from Biolegend (San Diego, California, USA). Anti-rabbit (4050-05) and anti-mouse (1031-05) secondary antibodies conjugated to horseradish peroxidase (HRP) were purchased from Southern Biotech; anti-rabbit secondary antibodies coupled to Alexa Fluor 488 (A-11034) or Alexa Fluor 647 (A-32733) came from Invitrogen. Antibodies for in vivo purpose: anti-PD-1 (BE0273, clone 29 F.1A12) and rat IgG2a anti-trinitrophenol isotype control (BE0089, clone LTF-2) were purchased from BioXcell (Lebanon, New Hampshire, USA).

\section{Phagocytosis and bone marrow-derived dendritic cell maturation assays}

$B M D C s$. Bone marrow-derived dendritic cells (BMDCs) were generated from bone marrow of femurs and tibias of C57BL/6 mice. First, bone marrows were collected purging bones with PBS supplemented with Pen/ Strep and 2\% FBS. Then, red blood cells were lysed with $5 \mathrm{~mL}$ of lysis buffer (BioLegend). After filtration, through a $70 \mu \mathrm{m}$ cell strainer, and washing, cells were resuspended in RPMI 1640 medium supplemented with Pen/ Strep, $10 \mathrm{mM}$ HEPES, 1\% Non-Essential Amino Acids Solutions, 10\% FBS, $50 \mathrm{nM} \quad \beta$-mercaptoethanol, $20 \mathrm{ng} / \mathrm{ml}$ of recombinant granulocytemacrophage colony-stimulating factor (GM-CSF) and $20 \mathrm{ng} / \mathrm{ml}$ of FMSlike tyrosine kinase 3 ligand (FLT3L) (Peprotech, Rocky Hill, New Jersey, USA) (complete medium) and seeded into 6-well plates at $7.5 \times 10^{5} / \mathrm{mL}$. After three days of culture, $1 \mathrm{~mL}$ of complete medium was added to each well and after three additional days, half of the culture medium was replaced. On day 7 BMDCs were harvested and resuspended at $2 \times 10^{5} / \mathrm{mL}$ for co-culture. 
A

- Cells s.c.
- CER $50 \mathrm{mg} / \mathrm{kg}$ i.p.
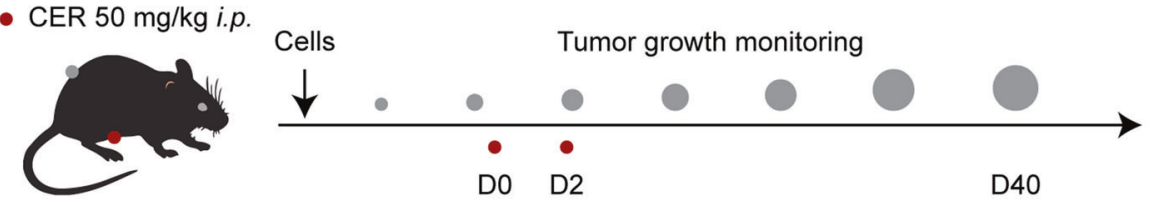

B $\bullet$ WT mice + vehicle $\bullet$ WT mice + CER $\bullet$ Foxn $1^{n u}$ mice + vehicle $\bullet$ Foxn $1^{\text {nu }}$ mice + CER
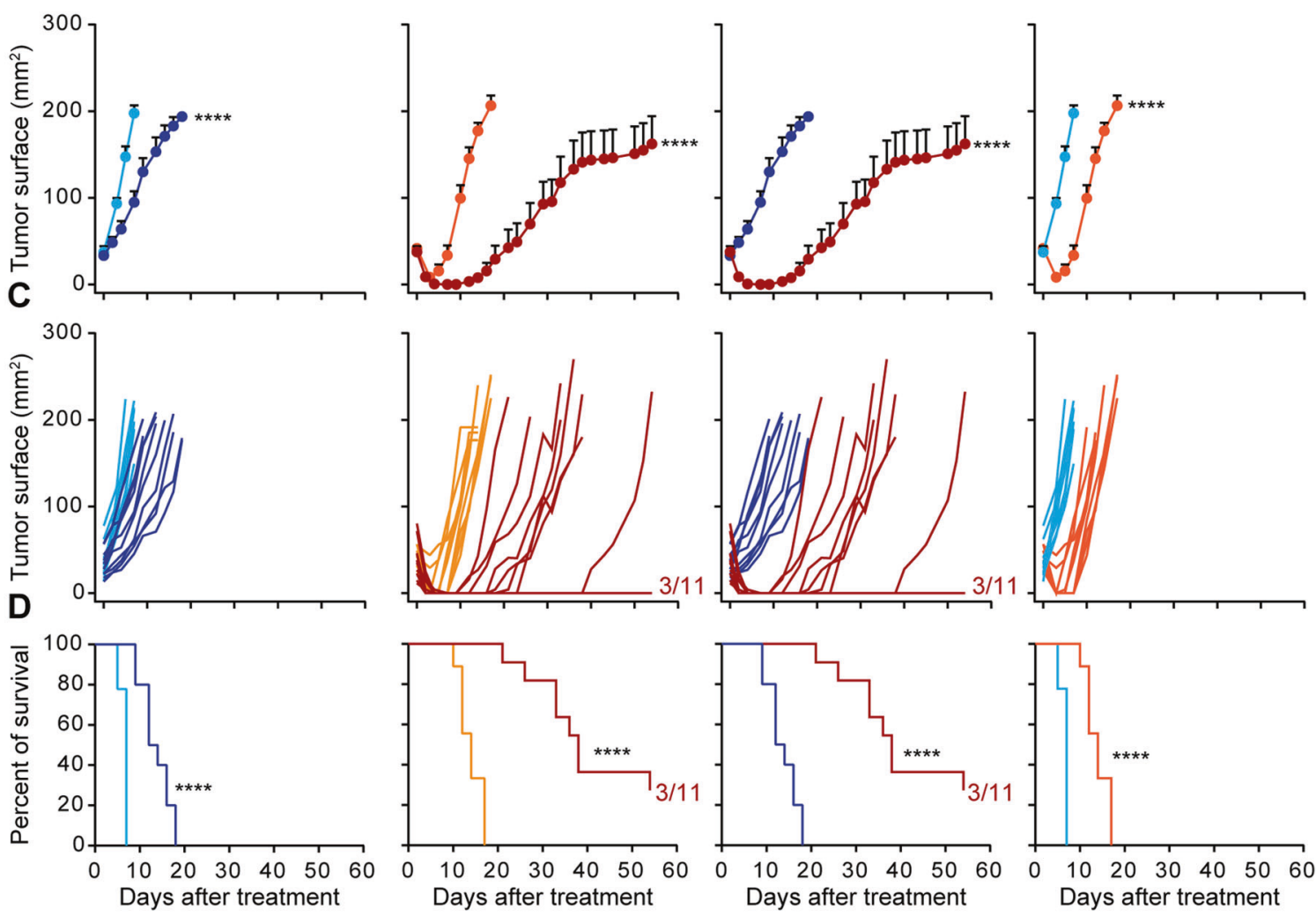

E

$\mathbf{F}$
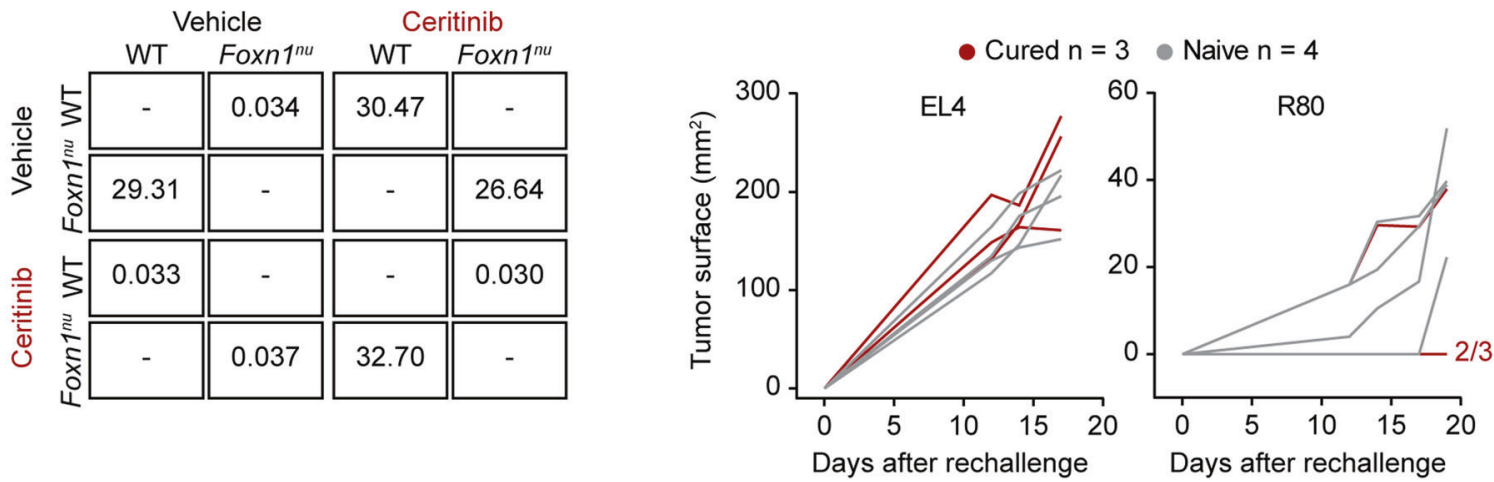

Fig. 6 Immune-dependent effect of ceritinib in ALK-driven lymphoma. One million NPM1-ALK ${ }^{+}$R80 cells were injected into the right flank of C57BL/6 or Foxn $1^{\text {nu }}$ mice. When tumors reached a surface of $30-35 \mathrm{~mm}^{2}$ mice were randomized and treated with ceritinib (CER, $50 \mathrm{mg} / \mathrm{Kg} \mathrm{i}$. p.) or vehicle control on the day of the randomization (d0) and 2 days later (d2) (A). Tumor surface is represented as mean \pm SEM of mice belonging to the same group (B) or for single mice (C). Survival is depicted in $\mathbf{D}$. Hazard ratio (Mantel-Haenszel) relative to the comparison between survivals of immunocompetent vs immunodeficient mice or vehicle-treated vs ceritinib-treated is shown in $\mathbf{E}$. Vehicle immunocompetent $n=10$; vehicle immunodeficient $n=9$; CER immunocompetent $n=11$; CER immunodeficient $n=9$. tumor growth curves were compared using a type II ANOVA test, while statistical significance of survival was calculated using the Log-rank test. ${ }^{* * * *} p<$ 0.0001 . Cured mice $(n=3)$ and naïve controls $(n=4)$ were challenged with $1 \times 10^{6}$ R80 into the left flank and $5 \times 10^{5}$ of unrelated lymphoma cells, EL4, into the right flank. Tumor growths of EL4 and R80 lymphomas are shown in F. 
A

- Cells S.C.

- CER $50 \mathrm{mg} / \mathrm{kg}$ or vehicle i.p.
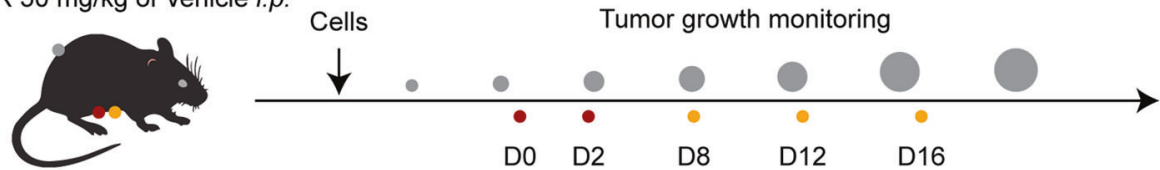

- Vehicle + isotype control - CER + isotype control Anti-PD-1 C CER + anti-PD-1

B

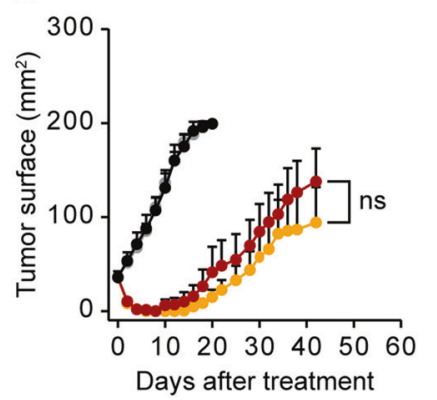

C

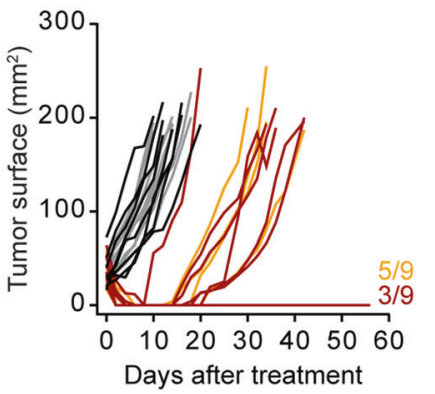

D

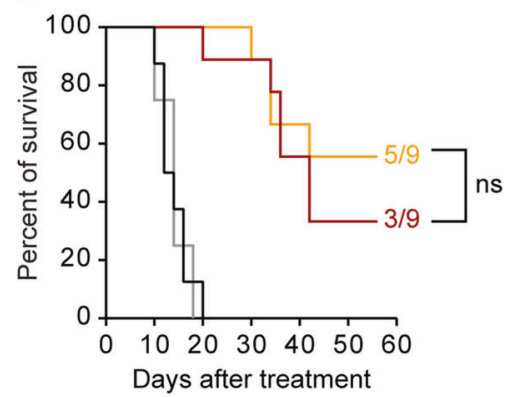

Fig. 7 In vivo combination of ceritinib and anti-PD-1. One million of murine NPM1-ALK ${ }^{+}$R80 cells were injected into the right flank of syngeneic mice (C57BL/6). When tumors reached a surface of $30-35 \mathrm{~mm}^{2}$ mice were randomized and treated with ceritinib (CER, $50 \mathrm{mg} / \mathrm{Kg}$, i. p.) or vehicle control on the day of the randomization (d0) and 2 days later (d2). Then, on d8, d12, d16 mice were injected i.p. with $200 \mu \mathrm{g}$ of anti-PD-1 or isotype control antibodies (A). Tumor surface is represented as mean \pm SEM of mice belonging to the same group (B) or for single mice (C). Survival is depicted in D. Vehicle + isotype $n=8$; vehicle + anti-PD- $n=8$; CER + isotype $n=9$; CER + anti-PD-1 $n=9$. Comparison between tumor growth curves was assessed using a type II ANOVA test, while statistical significance of survival data was calculated using the Log-rank test. ns non-significant.

Tumor cells. R80 cells were stained with $0.5 \mu \mathrm{M}$ of the CellTracker green 5chloromethylfluorescein diacetate (CMFDA; Thermo Fisher Scientific) (for the phagocytosis assay) or left unstained (for the BMDC maturation assay). Briefly, cells were harvested and resuspended at $2 \times 10^{6} / \mathrm{mL}$ in serum-free medium and incubated with CMFDA for $15 \mathrm{~min}$ at $37^{\circ} \mathrm{C} / 5 \% \mathrm{CO}_{2}$. Free CMFDA was neutralized adding an equal volume of FBS. After centrifugation, cells were resuspended in serum-containing medium and incubated for $30 \mathrm{~min}$ at $37^{\circ} \mathrm{C} / 5 \% \mathrm{CO}_{2}$. Afterwards, R80 cells were treated and subsequently co-cultured with BMDCs at 1:4 ratio (BMDCs:murine tumor cells).

Co-culture. After $4 \mathrm{~h}$, cells were detached with a cell scraper, and cell suspensions were transferred to 96-well plates. After washing with $150 \mu \mathrm{l} /$ well of cold $\left(4^{\circ} \mathrm{C}\right) \mathrm{PBS}$, cells were stained with $50 \mu \mathrm{l} /$ well of anti-CD $11 \mathrm{C}$ antibody coupled to the PE-Vio770 fluorophore diluted in PBS/1\% BSA. After $30 \mathrm{~min}$ of incubation on ice, cells were washed and fixed with $3.7 \%$ formaldehyde diluted in PBS. Finally, cells were analyzed by means of a MACSQuant flow cytometer, and data analyzed with FlowJo software. Percentage of phagocytized cells equaled to the percentage of CMFDA ${ }^{+}$ cells within $\mathrm{CD}^{11 \mathrm{c}^{+}}$BMDCs (phagocytosis assay) [66]. BMDCs maturation assay was performed after $24 \mathrm{~h}$ of co-culture. First, cells were detached with a cell scraper and transferred to 96-well plates. After washing with $150 \mu \mathrm{l} /$ well of cold PBS, cells were incubated with $50 \mu \mathrm{l} /$ well of the LIVE/ DEAD fixable violet dead cell stain kit (Invitrogen) for 15 min on ice. After 2 additional washings, cells were stained with fluorescent anti-CD11c, -CD86, and -la/le antibodies for $30 \mathrm{~min}$ on ice. Finally, cells were fixed with $3.7 \%$ formaldehyde (diluted in PBS) and fluorescence intensity of single cells was quantified using a MACSQuant flow cytometer. Data were analyzed with FlowJo software. Fold increase of expression was calculated using the median of fluorescence intensity of each marker [67].

\section{In vivo experiments}

Animals. Six- to eight-week-old female wild-type C57BL/6 and Foxn $1^{\text {nu }}$ mice were purchased from Envigo (Indianapolis, Indiana, USA) and housed in a pathogen-free, temperature-controlled environment with 12-h day and night cycles. They received water and food ad libitum. Animal experiments were conducted in compliance with the EU Directive 63/2010 and with protocols \#18967-2019020612051799v2 and \#288932021010810535218 V2 approved by the local Ethical Committee (" $\mathrm{C}$. Darwin" registered at the French Ministry of Research).
Vaccination assay. R80 cells were treated with ceritinib or mitoxantrone to reach $50-70 \%$ mortality. After washing with cold $\left(4^{\circ} \mathrm{C}\right) \mathrm{PBS}$, they were resuspended at $10-50 \times 10^{6} / \mathrm{mL}$. $100 \mu \mathrm{l}$ of dying cells were injected subcutaneously (s.c.) into the left flank of immunocompetent C57BL/6 animals. One-two weeks later, $1 \times 10^{6}$ of live R80 tumor cells were injected s.c. into the opposite flank and tumor appearance and growth were monitored. Tumor length and width were measured with a caliper 3 times/ week and tumor areas were calculated multiplying length and width. Mice were sacrificed when tumors reached $1.8-2 \mathrm{~cm}^{2}$ or if depicting any signs of discomfort. Tumor growth was analyzed with the TumGrowth software package [68], while survival was assessed using the Log-rank test with GraphPad Prism software 9 (San Diego, California, USA).

Tumor growth. C57BL/6 and Foxn $1^{\text {nu }}$ mice were injected with $1 \times 10^{6}$ R80 tumor cells s.c. into the right flank. When tumors reached a surface of approximately $30-35 \mathrm{~mm}^{2}$, mice were randomized based on tumor size and treated. No blinding was done. Ceritinib, diluted in $76 \%$ physiological solution, $10 \%$ Tween $80,10 \%$ polyethylene glycol (PEG) 400 , and $4 \%$ DMSO, was administered intraperitoneal (i.p.) twice (on the day of the randomization and 2 days later) at $50 \mathrm{mg} / \mathrm{kg}$. $200 \mu \mathrm{g}$ of anti-PD-1 or isotype control, diluted in $200 \mu$ l of PBS, were administered i.p, 6, 10, and 14 days after the last injection of ceritinib. Tumor length and width were assessed with a caliper 3 times/week and tumor areas were calculated multiplying length and width. Mice were sacrificed when tumors reached $1.8-2 \mathrm{~cm}^{2}$ or if depicting any signs of discomfort. Tumor growth was analyzed with the TumGrowth software package [68], while survival was assessed using the Log-rank test with GraphPad Prism software 9.

\section{Statistical analyses}

In vitro- and ex-vivo-data are presented as individual replicates or as means $\pm S D$ of technical replicates of at least three independent experiments as specified in the figure legends. No statistical method was used to choose sample size. Statistical significance was calculated using the two-tailed Student's $t$ test with Welch's correction (no assumption of equal SDs). Holm-Sidak correction for multiple comparison was applied when using multiple Student's $t$ tests. Statistical analysis was performed using GraphPad Prism software 9.

In vivo-tumor growth data are depicted as means \pm SEM of mice belonging to the same group. No statistical method was used to choose sample size. Normal distribution of data was verified plotting tumor areas 
on a quantile-quantile plot. Statistical significance was calculated using the type II ANOVA test using the TumGrowth software package [68] freely available at https://github.com/kroemerlab. Analysis of survival was performed using the Log-rank test with GraphPad Prism software 9 or Chi-square test.

Statistical significance was represented as following: ${ }^{*} p<0.05,{ }^{* *} p<0.01$, ${ }^{* * *} p<0.001,{ }^{* * * *} p<0.0001$

\section{REFERENCES}

1. Podlaha O, Riester M, De S, Michor F. Evolution of the cancer genome. Trends Genet. 2012;28:155-63.

2. Vesely MD, Kershaw MH, Schreiber RD, Smyth MJ. Natural innate and adaptive immunity to cancer. Annu Rev Immunol. 2011;29:235-71.

3. Woo SR, Corrales L, Gajewski TF. Innate immune recognition of cancer. Annu Rev Immunol. 2015:33:445-74.

4. Alderton GK, Bordon Y. Tumour immunotherapy-leukocytes take up the fight. Nat Rev Immunol. 2012;12:237.

5. Kortlever RM, Sodir NM, Wilson CH, Burkhart DL, Pellegrinet L, Brown Swigart L, et al. Myc cooperates with Ras by programming inflammation and immune suppression. Cell 2017;171:1301-15. e14

6. Welte T, Kim IS, Tian L, Gao X, Wang H, Li J, et al. Oncogenic mTOR signalling recruits myeloid-derived suppressor cells to promote tumour initiation. Nat Cell Biol. 2016;18:632-44.

7. Bradley SD, Chen Z, Melendez B, Talukder A, Khalili JS, Rodriguez-Cruz T, et al. BRAFV600E co-opts a conserved MHC Class I internalization pathway to diminish antigen presentation and CD8 + T-cell recognition of melanoma. Cancer Immunol Res. 2015;3:602-9.

8. Hoos A, Britten C. The immuno-oncology framework: enabling a new era of cancer therapy. Oncoimmunology 2012;1:334-9.

9. Hodi FS, O'Day SJ, McDermott DF, Weber RW, Sosman JA, Haanen JB, et al. Improved survival with ipilimumab in patients with metastatic melanoma. $\mathrm{N}$ Engl J Med. 2010;363:711-23.

10. Motzer RJ, Escudier B, McDermott DF, George S, Hammers HJ, Srinivas S, et al. Nivolumab versus everolimus in advanced renal-cell carcinoma. N Engl J Med. 2015:373:1803-13.

11. Gandhi L, Rodriguez-Abreu D, Gadgeel S, Esteban E, Felip E, De Angelis F, et al. Pembrolizumab plus chemotherapy in metastatic non-small-cell lung cancer. $\mathrm{N}$ Engl J Med. 2018;378:2078-92.

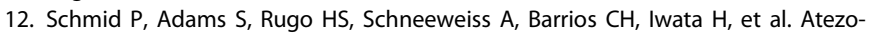
lizumab and Nab-Paclitaxel in advanced triple-negative breast cancer. $\mathrm{N}$ Engl J Med. 2018;379:2108-21.

13. Casares N, Pequignot MO, Tesniere A, Ghiringhelli F, Roux S, Chaput N, et al. Caspase-dependent immunogenicity of doxorubicin-induced tumor cell death. J Exp Med. 2005;202:1691-701.

14. Aaes TL, Kaczmarek A, Delvaeye T, De Craene B, De Koker S, Heyndrickx L, et al. Vaccination with necroptotic cancer cells induces efficient anti-tumor immunity. Cell Rep. 2016;15:274-87.

15. Zhang Z, Zhang Y, Xia S, Kong Q, Li S, Liu X, et al. Gasdermin E suppresses tumour growth by activating anti-tumour immunity. Nature 2020;579:415-20.

16. Efimova I, Catanzaro E, Van der Meeren L, Turubanova VD, Hammad H, Mishchenko TA, et al. Vaccination with early ferroptotic cancer cells induces efficient antitumor immunity. J Immunother Cancer. 2020;8.

17. Obeid M, Tesniere A, Ghiringhelli F, Fimia GM, Apetoh L, Perfettini JL, et al. Calreticulin exposure dictates the immunogenicity of cancer cell death. Nat Med. 2007;13:54-61.

18. Ma $\mathrm{Y}$, Adjemian $\mathrm{S}$, Mattarollo $\mathrm{SR}$, Yamazaki T, Aymeric $\mathrm{L}$, Yang $\mathrm{H}$, et al. Anticancer chemotherapy-induced intratumoral recruitment and differentiation of antigenpresenting cells. Immunity 2013;38:729-41.

19. Apetoh L, Ghiringhelli F, Tesniere A, Obeid M, Ortiz C, Criollo A, et al. Toll-like receptor 4-dependent contribution of the immune system to anticancer chemotherapy and radiotherapy. Nat Med. 2007;13:1050-9.

20. Sistigu A, Yamazaki T, Vacchelli E, Chaba K, Enot DP, Adam J, et al. Cancer cellautonomous contribution of type I interferon signaling to the efficacy of chemotherapy. Nat Med. 2014;20:1301-9.

21. Fucikova J, Truxova I, Hensler M, Becht E, Kasikova L, Moserova I, et al. Calreticulin exposure by malignant blasts correlates with robust anticancer immunity and improved clinical outcome in AML patients. Blood 2016;128:3113-24.

22. Peng RQ, Chen YB, Ding $Y$, Zhang R, Zhang $X, Y u$ XJ, et al. Expression of calreticulin is associated with infiltration of T-cells in stage IIIB colon cancer. World J Gastroenterol. 2010;16:2428-34.

23. Fucikova J, Becht E, Iribarren K, Goc J, Remark R, Damotte D, et al. Calreticulin expression in human non-small cell lung cancers correlates with increased accumulation of antitumor immune cells and favorable prognosis. Cancer Res. 2016;76:1746-56.
24. Kasikova L, Hensler M, Truxova I, Skapa P, Laco J, Belicova L, et al. Calreticulin exposure correlates with robust adaptive antitumor immunity and favorable prognosis in ovarian carcinoma patients. J Immunother Cancer. 2019;7:312.

25. Yamazaki T, Hannani D, Poirier-Colame V, Ladoire S, Locher C, Sistigu A, et al. Defective immunogenic cell death of HMGB1-deficient tumors: compensatory therapy with TLR4 agonists. Cell Death Differ. 2014;21:69-78.

26. Ye Z, Dong H, Li Y, Ma T, Huang H, Leong HS, et al. Prevalent homozygous deletions of Type I interferon and defensin genes in human cancers associate with immunotherapy resistance. Clin Cancer Res. 2018;24:3299-308.

27. Aliagas E, Vidal A, Texido L, Ponce J, Condom E, Martin-Satue M. High expression of ecto-nucleotidases CD39 and CD73 in human endometrial tumors. Mediators Inflamm. 2014;2014:509027.

28. Galluzzi L, Buque A, Kepp O, Zitvogel L, Kroemer G. Immunological effects of conventional chemotherapy and targeted anticancer agents. Cancer Cell. 2015;28:690-714.

29. Petroni G, Buque A, Zitvogel L, Kroemer G, Galluzzi L. Immunomodulation by targeted anticancer agents. Cancer Cell. 2021;39:310-45.

30. Capdeville R, Buchdunger E, Zimmermann J, Matter A. Glivec (STI571, imatinib), a rationally developed, targeted anticancer drug. Nat Rev Drug Discov. 2002;1:493-502.

31. Delahaye NF, Rusakiewicz S, Martins I, Menard C, Roux S, Lyonnet L, et al. Alternatively spliced NKp30 isoforms affect the prognosis of gastrointestinal stromal tumors. Nat Med. 2011;17:700-7.

32. Rusakiewicz S, Semeraro M, Sarabi M, Desbois $M$, Locher $C$, Mendez $R$, et al. Immune infiltrates are prognostic factors in localized gastrointestinal stromal tumors. Cancer Res. 2013;73:3499-510.

33. Zitvogel L, Rusakiewicz S, Routy B, Ayyoub M, Kroemer G. Immunological offtarget effects of imatinib. Nat Rev Clin Oncol. 2016;13:431-46.

34. Balachandran VP, Cavnar MJ, Zeng S, Bamboat ZM, Ocuin LM, Obaid H, et al. Imatinib potentiates antitumor $T$ cell responses in gastrointestinal stromal tumor through the inhibition of Ido. Nat Med. 2011;17:1094-100.

35. Liu P, Zhao L, Pol J, Levesque S, Petrazzuolo A, Pfirschke C, et al. Crizotinibinduced immunogenic cell death in non-small cell lung cancer. Nat Commun. 2019;10:1486.

36. Morris SW, Kirstein MN, Valentine MB, Dittmer KG, Shapiro DN, Saltman DL, et al. Fusion of a kinase gene, ALK, to a nucleolar protein gene, NPM, in non-Hodgkin's lymphoma. Science 1994;263:1281-4.

37. Wan W, Albom MS, Lu L, Quail MR, Becknell NC, Weinberg LR, et al. Anaplastic lymphoma kinase activity is essential for the proliferation and survival of anaplastic large-cell lymphoma cells. Blood 2006;107:1617-23.

38. Ng SY, Yoshida N, Christie AL, Ghandi M, Dharia NV, Dempster J, et al. Targetable vulnerabilities in T- and NK-cell lymphomas identified through preclinical models. Nat Commun. 2018;9:2024.

39. Voena C, Conte C, Ambrogio C, Boeri Erba E, Boccalatte F, Mohammed S, et al. The tyrosine phosphatase Shp2 interacts with NPM-ALK and regulates anaplastic lymphoma cell growth and migration. Cancer Res. 2007;67:4278-86.

40. Ceccon M, Mologni L, Bisson W, Scapozza L, Gambacorti-Passerini C. Crizotinibresistant NPM-ALK mutants confer differential sensitivity to unrelated Alk inhibitors. Mol Cancer Res. 2013;11:122-32.

41. Hallberg B, Palmer RH. The role of the ALK receptor in cancer biology. Ann Oncol. 2016;27:iii4-iii15. Suppl 3

42. Menotti M, Ambrogio C, Cheong TC, Pighi C, Mota I, Cassel SH, et al. WiskottAldrich syndrome protein (WASP) is a tumor suppressor in T cell lymphoma. Nat Med. 2019;25:130-40.

43. Forveille S, Humeau J, Sauvat A, Bezu L, Kroemer G, Kepp O. Quinacrine-mediated detection of intracellular ATP. Methods Enzymol. 2019;629:103-13.

44. Kepp O, Senovilla L, Vitale I, Vacchelli E, Adjemian S, Agostinis P, et al. Consensus guidelines for the detection of immunogenic cell death. Oncoimmunology 2014;3:e955691.

45. Tesniere A, Schlemmer F, Boige V, Kepp O, Martins I, Ghiringhelli F, et al. Immunogenic death of colon cancer cells treated with oxaliplatin. Oncogene 2010;29:482-91.

46. Singh S, Jaigirdar AA, Mulkey F, Cheng J, Hamed SS, Li Y, et al. FDA approval summary: lurbinectedin for the treatment of metastatic small cell lung cancer. Clin Cancer Res. 2020;27:2378-2382.

47. Mullard A. FDA approves first BCMA-targeted therapeutic. Nat Rev Drug Discov. 2020;19:659.

48. Tan DS, Araujo A, Zhang J, Signorovitch J, Zhou ZY, Cai X, et al. Comparative efficacy of Ceritinib and Crizotinib as initial ALK-targeted therapies in previously treated advanced NSCLC: an adjusted comparison with external controls. J Thorac Oncol. 2016:11:1550-7.

49. Kasamon YL, de Claro RA, Wang Y, Shen YL, Farrell AT, Pazdur R. FDA approval summary: nivolumab for the treatment of relapsed or progressive classical hodgkin lymphoma. Oncologist 2017;22:585-91. 
50. Ansell SM, Lesokhin AM, Borrello I, Halwani A, Scott EC, Gutierrez M, et al. PD-1 blockade with nivolumab in relapsed or refractory Hodgkin's lymphoma. N Engl J Med. 2015;372:311-9.

51. Cathcart K, Pinilla-Ibarz J, Korontsvit T, Schwartz J, Zakhaleva V, Papadopoulos EB, et al. A multivalent bcr-abl fusion peptide vaccination trial in patients with chronic myeloid leukemia. Blood 2004;103:1037-42.

52. Pulford K, Falini B, Banham AH, Codrington D, Roberton $H$, Hatton $C$, et al. Immune response to the ALK oncogenic tyrosine kinase in patients with anaplastic large-cell lymphoma. Blood 2000;96:1605-7.

53. Ait-Tahar K, Damm-Welk C, Burkhardt B, Zimmermann M, Klapper W, Reiter A, et al. Correlation of the autoantibody response to the ALK oncoantigen in pediatric anaplastic lymphoma kinase-positive anaplastic large cell lymphoma with tumor dissemination and relapse risk. Blood 2010;115:3314-9.

54. Galluzzi L, Buque A, Kepp O, Zitvogel L, Kroemer G. Immunogenic cell death in cancer and infectious disease. Nat Rev Immunol. 2017;17:97-111.

55. Pietrocola F, Pol J, Vacchelli E, Rao S, Enot DP, Baracco EE, et al. Caloric restriction mimetics enhance anticancer immunosurveillance. Cancer Cell. 2016:30:147-60.

56. Passoni L, Gallo B, Biganzoli E, Stefanoni R, Massimino M, Di Nicola M, et al. In vivo T-cell immune response against anaplastic lymphoma kinase in patients with anaplastic large cell lymphomas. Haematologica 2006;91:48-55.

57. Rigaud C, Abbou S, Minard-Colin V, Geoerger B, Scoazec JY, Vassal G, et al. Efficacy of nivolumab in a patient with systemic refractory ALK+ anaplastic large cell lymphoma. Pediatr Blood Cancer. 2018;65.

58. Hebart $\mathrm{H}$, Lang $\mathrm{P}$, Woessmann $\mathrm{W}$. Nivolumab for refractory anaplastic large cell lymphoma: a case report. Ann Intern Med. 2016;165:607-8.

59. Chiarle R, Martinengo C, Mastini C, Ambrogio C, D'Escamard V, Forni G, et al. The anaplastic lymphoma kinase is an effective oncoantigen for lymphoma vaccination. Nat Med. 2008;14:676-80.

60. Metivier D, Dallaporta B, Zamzami N, Larochette N, Susin SA, Marzo I, et al. Cytofluorometric detection of mitochondrial alterations in early CD95/Fas/APO-1triggered apoptosis of Jurkat $T$ lymphoma cells. Comparison of seven mitochondrion-specific fluorochromes. Immunol Lett. 1998;61:157-63.

61. Zamzami N, Maisse C, Metivier D, Kroemer G. Measurement of membrane permeability and the permeability transition of mitochondria. Methods Cell Biol. 2007;80:327-40

62. Liu P, Zhao L, Kepp O, Kroemer G. Quantitation of calreticulin exposure associated with immunogenic cell death. Methods Enzymol. 2020;632:1-13.

63. Humeau J, Levesque S, Kroemer G, Pol JG. Gold standard assessment of immunogenic cell death in oncological mouse models. Methods Mol Biol. 2019;1884:297-315.

64. Zhao L, Liu P, Kepp O, Kroemer G. Methods for measuring HMGB1 release during immunogenic cell death. Methods Enzymol. 2019;629:177-93.

65. Wang Y, Martins I, Ma Y, Kepp O, Galluzzi L, Kroemer G. Autophagy-dependent ATP release from dying cells via lysosomal exocytosis. Autophagy 2013;9:1624-5.

66. Cerrato G, Liu P, Martins I, Kepp O, Kroemer G. Quantitative determination of phagocytosis by bone marrow-derived dendritic cells via imaging flow cytometry. Methods Enzymol. 2020;632:27-37.

67. Liu P, Zhao L, Loos F, Marty C, Xie W, Martins I, et al. Immunosuppression by mutated calreticulin released from malignant cells. Mol Cell. 2020;77:748-60. e9

68. Enot DP, Vacchelli E, Jacquelot N, Zitvogel L, Kroemer G. TumGrowth: an openaccess web tool for the statistical analysis of tumor growth curves. Oncoimmunology 2018;7:e1462431.

\section{ACKNOWLEDGEMENTS}

The authors thank the CRC core facilities. The authors are grateful to Dr. Meggetto, Dr. Ceccon, Prof. Gambacorti-Passerini, Dr. Ducray, Prof. Chiarle, and Dr. Poggio for providing cell lines. The authors thank the "Fédération Enfants et Santé" and "Société Française des Cancers de I'Enfant". GK is supported by the Ligue contre le Cancer (équipe labellisée); Agence National de la Recherche (ANR) - Projets blancs; ANR under the frame of E-Rare-2, the ERA-Net for Research on Rare Diseases; Fondation "ARC pour la recherche sur le cancer"; Cancéropôle lle-de-France; Chancelerie des universités de Paris (Legs Poix), Fondation pour la Recherche Médicale (FRM); a donation by Elior; European Research Area Network on Cardiovascular Diseases (ERACVD, MINOTAUR); Gustave Roussy Odyssea, the European Union Horizon 2020 Project
Oncobiome; Fondation Carrefour; Institut National du Cancer (INCa); Inserm (HTE); Institut Universitaire de France; the LabEx Immuno-Oncology (ANR-18-IDEX-0001) the RHU Torino Lumière; the Seerave Foundation; the SIRIC Stratified Oncology Cell DNA Repair and Tumor Immune Elimination (SOCRATE); and the SIRIC Cancer Research and Personalized Medicine (CARPEM). OK receives funding from the DIM elicit of the lle de France. AP, VMC and GK were supported by the Horizon 2020/ European Union grant Alkatraz. AP has been supported by European Union Horizon 2020 Marie Skłodowska-Curie Innovative Training Network (ITN-ETN) Grant, Award No.: 675712 and the Fondation "ARC pour la recherche sur le cancer".

\section{AUTHOR CONTRIBUTIONS}

AP performed the in vitro and in vivo experiments. MPL contributed to the in vivo experiments. IM contributed to the cytometry-based experiments. PL contributed to the ex vivo experiments. AP and OK prepared the figures. VMC reviewed and supervised the study. AP, MCM, and GK conceived the study, interpreted data, supervised the whole set of experiments, and wrote the manuscript. All authors have read and agreed to the published version of the manuscript.

\section{ETHICS STATEMENT}

Animal experiments were conducted in compliance with the EU Directive 63/2010 and with protocols \#18967-2019020612051799v2 and \#28893-2021010810535218v2 approved by the local Ethical Committee ("C. Darwin" registered at the French Ministry of Research).

\section{COMPETING INTERESTS}

GK has been holding research contracts with Daiichi Sankyo, Glaxo Smyth Kline, Eleor, Institut Mérieux, Kaleido, Lytix Pharma, PharmaMar, Sotio, and Vasculox/Tioma. GK is on the Board of Directors of the Bristol Myers Squibb Foundation France. GK is a scientific co-founder of everlmmune, Samsara Therapeutics and Therafast Bio. OK is a scientific co-founder of Samsara Therapeutics. VMC has been holding research contracts with Roche, Bristol Myers Squibb, and Novartis.

\section{ADDITIONAL INFORMATION}

Supplementary information The online version contains supplementary material available at https://doi.org/10.1038/s41419-021-03997-x.

Correspondence and requests for materials should be addressed to G.K.

Reprints and permission information is available at http://www.nature.com/ reprints

Publisher's note Springer Nature remains neutral with regard to jurisdictional claims in published maps and institutional affiliations.

\footnotetext{
Open Access This article is licensed under a Creative Commons

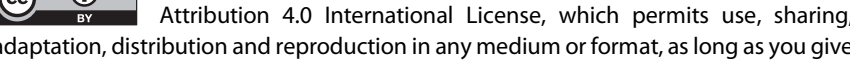
appropriate credit to the original author(s) and the source, provide a link to the Creative Commons license, and indicate if changes were made. The images or other third party material in this article are included in the article's Creative Commons license, unless indicated otherwise in a credit line to the material. If material is not included in the article's Creative Commons license and your intended use is not permitted by statutory regulation or exceeds the permitted use, you will need to obtain permission directly from the copyright holder. To view a copy of this license, visit http://creativecommons. org/licenses/by/4.0/.
}

(c) The Author(s) 2021 